FOSTERING THE ‘TIME IS NOW’ MENTALITY: THE ROLE OF OPEN DATA IN URBAN CLIMATE RESILIENCE

\author{
by \\ Keira Webster \\ BA, McGill University, 2015 \\ A major research paper \\ presented to Ryerson University \\ in partial fulfillment of the requirements for the degree of \\ Master of Planning \\ in \\ Urban Development
}

Toronto, Ontario, Canada, 2017

(C) Keira Webster, 2017 


\section{AUTHOR'S DECLARATION FOR ELECTRONIC SUBMISSION OF A MRP}

I hereby declare that I am the sole author of this MRP. This is a true copy of the MRP, including any required final revisions.

I authorize Ryerson University to lend this MRP to other institutions or individuals for the purpose of scholarly research.

I further authorize Ryerson University to reproduce this MRP by photocopying or by other means, in total or in part, at the request of other institutions or individuals for the purpose of scholarly research.

I understand that my MRP may be made electronically available to the public. 


\title{
FOSTERING THE 'TIME IS NOW’ MENTALITY: THE ROLE OF OPEN DATA IN URBAN CLIMATE RESILIENCE
}

(C) Keira Webster, 2017

\author{
Master of Planning \\ In \\ Urban Development \\ Ryerson University
}

\begin{abstract}
Climate change is a systemic issue embedded in and interconnected with the social and economic makeup of a city. Building urban climate resilience requires innovative, collaborative solutions that hinge upon the openness and availability of current and contextual data. Open data tools, in stimulating information sharing, civic engagement, and innovative products, can contribute to climate change planning, building lasting resilience. Through an exploratory research methodology, this paper explores 17 international use cases, providing a basis for the implementation of open data tools in the realm of urban climate resilience, through the following five themes: 1) risk and vulnerability assessment; 2) the inception of initiatives; 3) diverging approaches to preparedness; 4) community mobilization; and 5) mitigation and adaptation. This research aims to spark a dialogue on the intersection of open data tools in urban climate resilience strategies, demonstrating open data as an appropriate tool to cultivate shared understanding and collective action.
\end{abstract}

Key Words: Urban Resilience; Open Data; Climate Change; Urban Planning 


\section{ACKNOWLEDGEMENTS}

I would like to express a sincere and massive thank you to my supervisor, Dr. Pamela Robinson, for her insights and support from start to finish in this research. I have never been as inspired or challenged as I have during this research and I owe that to Pamela's guidance, critical mind, and passion for exploration.

Thank you as well to my second reader, Mary MacDonald. I am very grateful to benefit from her perspective and expertise in the environmental field.

I am very appreciative of the funding that helped support the development of this paper, granted by the Social Sciences and Humanities Research Council. I would not have been able to explore my research topic in such depth without the financial resources I was provided.

To the research team, Jean-Noé Landry, Bianca Wylie, and Pamela Robinson, as well as Open North and Geothink: working on the paper, How can we improve urban resilience with open data?, for the United Kingdom Open Data Institute, greatly influenced my thinking on the merging of these communities of practice. I am very thankful for the opportunity to play a role in this fantastic team as well as to further build on the use case analysis in my own paper. 


\section{TABLE OF CONTENTS}

AUTHOR'S DECLARATION FOR ELECTRONIC SUBMISSION OF A MRP............................ ii

ABSTRACT ................................................................................................................................. iii

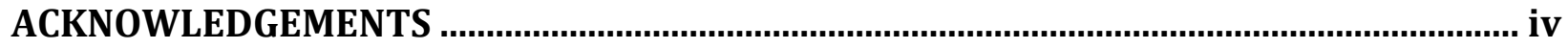

LIST OF FIGURES................................................................................................................ vii

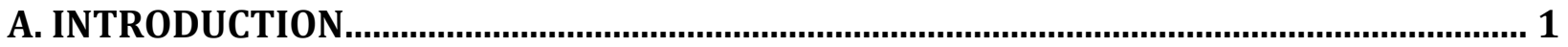

B. LITERATURE REVIEW $\ldots \ldots \ldots \ldots \ldots \ldots \ldots \ldots \ldots \ldots \ldots \ldots \ldots \ldots \ldots \ldots \ldots \ldots \ldots \ldots \ldots \ldots \ldots$

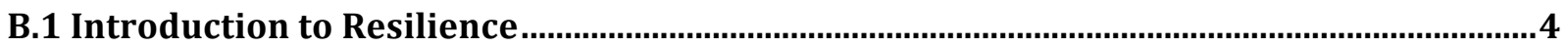

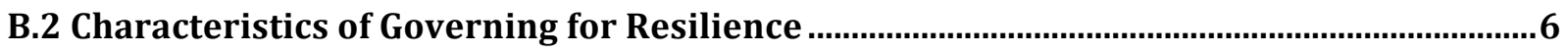

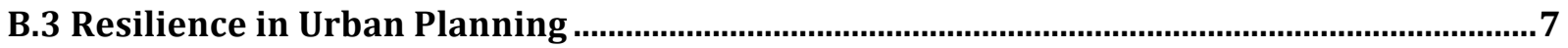

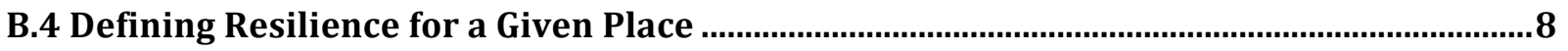

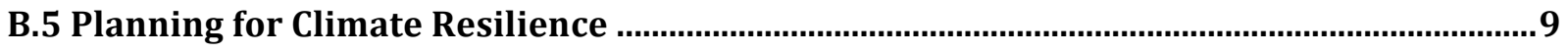

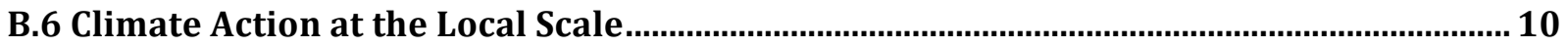

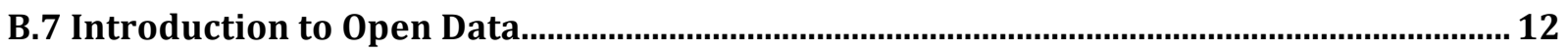

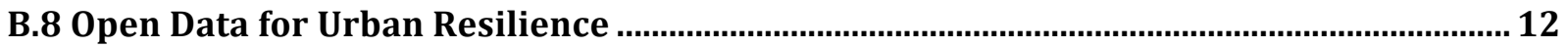

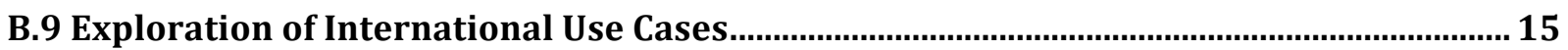

B.9.1 Open data to help inform and act on vulnerabilities associated with shocks and stresses

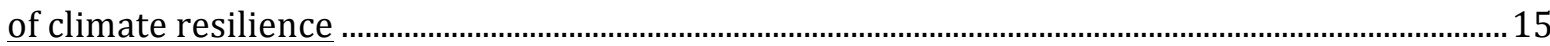

B.9.2 Considerations for Government-led and Community-led initiatives........................................18

B.9.3 Proactive versus reactive approaches ..................................................................................... 22

B.9.4 Community mobilization and collective action ........................................................................ 23

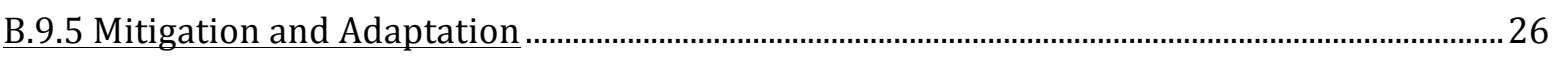

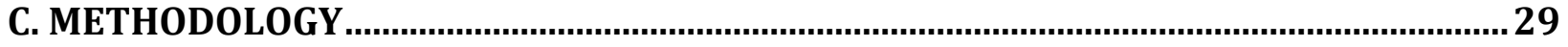

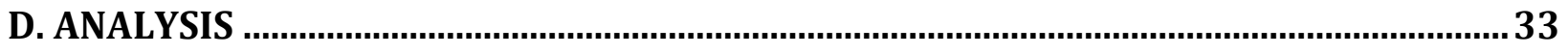

D.1 Open Data to help inform and act on Vulnerabilities associated with the Shocks and

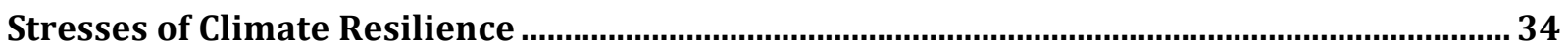

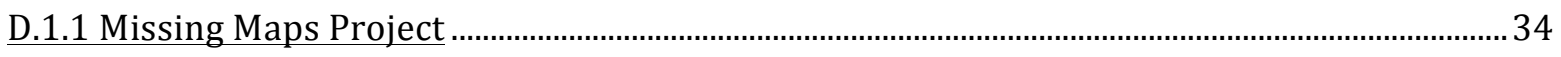

D.1.2 Deltares iD CIrcle Tool.................................................................................................................... 36

D.2 Considerations for Government-led and Community-led initiatives ................................ 38

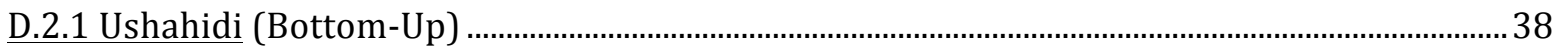

D.2.2 Climate-KIC Climathon (Top-Down) ........................................................................................ 39

D.2.3 Kathmandu Living Labs (Joint Bottom-Up and Top-Down)................................................... 40

D.3 Proactive versus Reactive approaches ............................................................................42

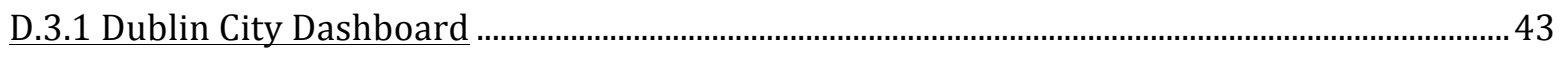

D.4 Community Mobilization and Collective Action..............................................................45

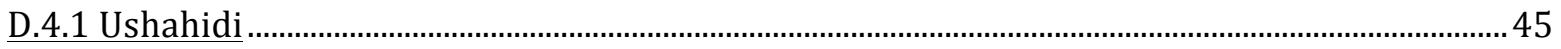

D.4.2 Earthquake emergency response in Christchurch, New Zealand............................................... 47

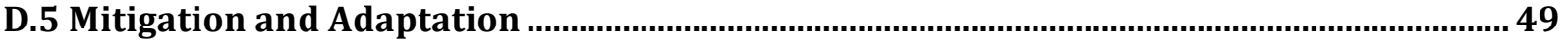

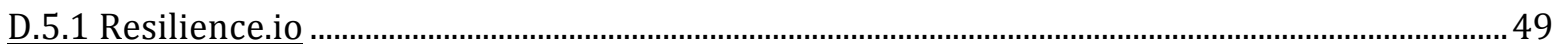




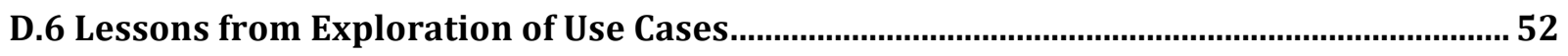

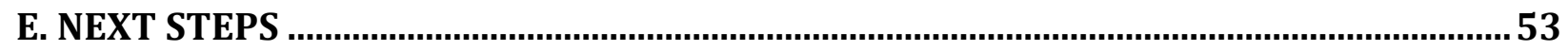

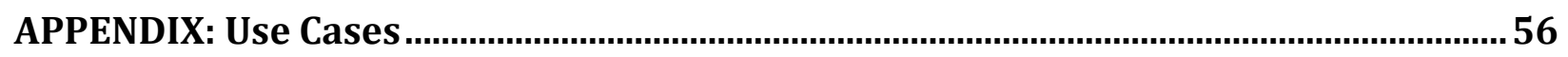

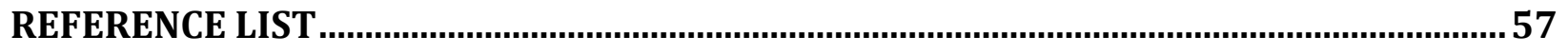

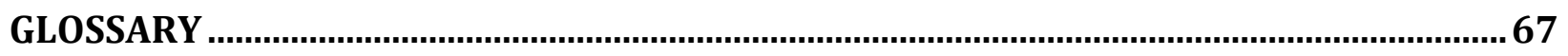




\section{LIST OF FIGURES}

Figure 1: Exploratory research process examining the role of open data in building urban climate resilience (p.31)

Figure 2: Interconnections between use cases and the five themes; the thickness of the arrow depicts the degree of use case overlap among various themes (p. 34) 


\section{A. INTRODUCTION}

As the devastating effects of climate change become increasingly pervasive, municipalities are developing strategies that focus on mitigating greenhouse gas emissions that are the source of global warming and adapting the built environment to endure the severe repercussions of a changing climate (Davoudi, 2009). Both mitigation and adaptation require community mobilization and collective action to achieve effective and resilient solutions (Dale et al, 2012). It is important to consider climate change not as an independent issue but rather an issue that is embedded in and interconnected with the social and economic makeup of a city (Berkowitz, 2015). Furthermore, cities are complex and multifaceted systems subject to the risks and uncertainties that arise from environmental, socioeconomic, and political circumstances (Mehmood, 2016). As such, governing for resilience in urban centres is a concept quickly gaining traction (Meerow et al, 2016; Beilin and Wilkinson, 2015; Rockefeller Foundation, 2017). Given the complexities and uncertainties of both urban areas and climate change, solutions require "innovative, systems deep approaches" that can tackle a diverse array of interconnected issues affecting both the short-term and the long-term, as opposed to issue-based independent strategies for mitigation and adaptation (Rodin, 2017, para 2). Yet, governing for resilience can be challenging as it is largely contextual and requires incorporation of short-term and longterm needs and goals. There is a need for a paradigm shift - a critical assessment of the status quo examining what tools and techniques - formal, informal, and in-between - could be useful in strengthening and improving the systems that constitute a city. New ways of thinking and dynamic approaches to confront the wicked problem that is climate change are imperative. In stimulating information sharing, civic engagement, and innovative products (Robinson and Johnson, 2016; Sieber and Johnson, 2015), open data tools can play a role in climate change planning to build systemic and lasting resilience.

Through an exploratory research methodology, this paper examines the role of open data tools in building urban climate resilience through a series of international use cases seeking to connect conceptual and critical thinking with on the ground actionable strategies. In approaching the need to build urban resilience when faced with the uncertain and unprecedented nature of climate change, this research turns to open data as an 
appropriate tool to cultivate a shared understanding and facilitate collective action. In essence, this paper aims to initiate a conversation on the intersection of open data tools in urban climate resilience strategies.

The core question framing this research is: how can open data tools and techniques be integrated within climate change planning to build urban resilience and instigate a sense of agency and collective action among stakeholders? To answer the core question, 17 international use cases (Appendix A), pertaining to the integration of open data in resilience planning, were explored through five themes. The themes include 1) the mapping of vulnerabilities; 2 ) inception of initiatives; 3 ) proactive and reactive approaches; 4) civic engagement; and 5) mitigation and adaptation. They provide a basis for the implementation of open data tools already taking place in the realm of urban climate resilience and hint at potential opportunities and challenges. Further, this research seeks to pinpoint how open data initiatives like the use cases can alter the way in which urban planners approach climate change adaptation and mitigation. The following inquiries frame the discussion, building upon the core question for this paper:

- How can open data strategies assist in facilitating civic engagement on climate change mitigation and adaptation?

- What various roles can open data play in planning for climate change (i.e. hackathons, apps, policy formation) and how do they build resilience?

- What collaborative practices can emerge from the incorporation of open data strategies for building climate resilience?

This research does not suggest that open data is the sole answer or a panacea to the vast issues facing urban resilience planning but rather, that there is a valuable and extensive opportunity for open data tools - ranging from reactive disaster mapping initiatives to network analyses exploring indirect impacts to real-time data visualizations - to contribute to and further cities' climate resilience goals. This paper aims to inform both the open data and resilience communities of practice about the potential for open data to assist with urban resilience strategies. Yet, it is ultimately the prerogative of local practitioners and 
residents to determine how open data best meets the context-specific needs, priorities, and problem definitions of their urban centres. 


\section{B. LITERATURE REVIEW}

The research, which is the foundation of this paper, is threefold: first, the literature establishes the context of the growing urban resilience movement, questions what it means for urban planning, and considers the urgent need for climate action at the local scale. The research then turns to open data highlighting its context, the opportunities and challenges of transparent and accountable data provision, and the manner in which open data tools can be employed to address many of the challenges, gaps, or priorities facing climate change planning. In general, there is a dearth of academic literature on the intersection between open data and urban climate resilience; many of the concerns or recommendations associated with climate change action at the local scale could be furthered through the integration of open data initiatives. For instance, open data tools can contribute to building engagement, increasing transparency, improving problem solving capabilities, and producing contextual technology (Janssen et al, 2012). Finally, the literature frames the discussion moving forward introducing five themes that draw parallels and points of intersection between the research in open data and urban resilience that are then used to explore the international use cases.

\section{B.1 Introduction to Resilience}

This paper approaches the problem of governing for resilience when confronted with a changing climate. There are a variety of definitions that stakeholders employ when developing strategies, enacting governance structures, or planning for resilience. While the term resilience is becoming more prevalent in urban planning and related fields such as engineering and disaster risk management, a weariness and critical approach to resilience is pertinent so that it does not become merely a buzzword. Rather, the meaning of the term and how it is operationalized need to be carefully considered through dialogue, planning, and action (Davoudi et al, 2017), incorporating context-specific priorities and risks.

The Rockefeller Foundation, through their 100 Resilient Cities (100 RC) movement, provides financial resources, information provision, and a global network for cities to build resilience. The movement is now coordinating and funding resilience initiatives in 100 cities around the world. Their definition of urban resilience "is the capacity of individuals 
communities, institutions, businesses, and systems within a city to survive, adapt, and grow no matter what kinds of chronic stresses and acute shocks they experience" (Rockefeller Foundation, 2017). Cities experience acute shocks - immediate and intense events that jeopardize a city - and chronic stresses - recurring, prolonged issues that diminish a city's foundation - from natural disasters to housing affordability to unemployment. In approaching urban resilience through the lens of a changing climate and when considering the Rockefeller Foundation's definition of urban resilience, acute shocks incorporate natural disasters such as earthquakes and floods arising from sea level rise or intense rain. Chronic stresses include persistent water shortages and issues of food security (Rockefeller Foundation, 2017). The Rockefeller Foundation's 100 Resilient Cities movement provides cities with resources to act on their specific sudden incidents and enduring pressures.

Endeavours in urban resilience can be approached through two disparate approaches: engineering resilience or the "mechanistic model of systems that can recover their original state aftershocks" and ecological resilience referring to the "evolutionary model enabling adaptation to disturbances" (Caputo et al, 2015, p.222). Engineering resilience can be envisioned as "bouncing back" to equilibrium; looking at the level of disruption or the time it takes to return to equilibrium post-disruption whereby the risk is attainable and quantifiable (Beilin and Wilkinson, 2015). In contrast, ecological resilience deals more with the "magnitude" that a system, generally socio-ecological systems, can endure within "critical thresholds" (Davoudi et al, 2012, p. 300; Carpenter et al, 2001). Lister (2015) considers resilience in the perspective of "an emerging policy concept" describing the term broadly as "the ability of an ecosystem to withstand and absorb change to prevailing environmental conditions; in an empirical sense, resilience is the amount of change or disruption an ecosystem can absorb and, following these change events, return to a recognizable steady state in which the system retains most of its structures, functions, and feedbacks" (p.14). The varying approaches to resilience influence the direction and interpretation of policy-making, planning, and decision-making that strive to realize urban centres that can withstand and adapt to the instant and enduring challenges in which they are confronted. 
Urban policy based upon engineering resilience or the "techno-scientific approach" would be prescriptive or rigid. An engineering resilience approach in policy acknowledges that there is one stable set of circumstances and when faced with change, systems are mechanical and must bounce back. In contrast, ecological resilience views systems as evolutionary and adaptable understanding that change is unavoidable and often unpredictable (Caputo et al, 2015). The major difference between the two interpretations is that engineering resilience considers one steady equilibrium whereas ecological resilience incorporates multiple equilibria that systems can reach when they extend beyond certain thresholds (Davoudi et al, 2012). The concept of social resilience also plays a role in the discussion, referring to the capabilities of communities to respond to pressures or traumas resulting from social, political, or environmental circumstances (Mehmood, 2016; Beilin and Wilkinson, 2015). Resilience thinking, particularly in the realm of urban planning, is becoming increasingly prominent - as can be seen with the 100 Resilient Cities movement. The multi-faceted and complex nature of resilience, incorporating varying and often, overlapping interpretations, promotes flexibility while also challenges practitioners to achieve clarity.

\section{B.2 Characteristics of Governing for Resilience}

Resilience is referred to in discourses involving sustainability, initiatives for climate change planning and disaster management, in affiliation with adaptive capacity, and as a measure for socio-ecological systems. As a practical or scientific term, resilience first originated in the field of ecology but has now proliferated throughout multiple disciplines (Carpenter et $\mathrm{al}, 2001)$. Carpenter et al (2001) note that there are three characteristics that outline resilience thinking or the "magnitude of disturbance that can be tolerated before a system moves into a different region of state space" (p. 766). The characteristics are: 1) the degree of change that a system can endure without having to change its architecture; 2) the extent to which the system has the ability to self-organize; and 3) the ability for the system to "build capacity to learn and adapt" (Carpenter et al, p.766). There is a need to bridge the gap between ideation and implementation, between academic theory and practice (Wagenaar and Wilkinson, 2015), to effectively govern for resilience addressing the complexities and uncertainties facing urban cities in a changing climate. 
In their paper, Introduction: Governing for Resilience, Beilin and Wilkinson (2015) introduce four themes that frame their discussion of resilience: 1) location of action; 2) scale; 3) social justice; and 4) local knowledge and memory. Location of the action considers the processes behind governing for resilience whether they are top-down, authority-driven or bottom-up, grassroots-based or somewhere in the middle, where resilience is addressed at either end simultaneously or collaboratively. Scale investigates the considerations and interactions at different scales, connections within a network, and approaching urban areas or local scales in resilience planning. The social justice theme includes economic resilience, inequalities, and the necessity to consider the uneven extent of power among stakeholders (Beilin and Wilkinson, 2015). The power dynamics can play a major role in determining the information withheld and disclosed, the framing of an issue, and the intensity of public involvement (Miller, 2008; Sinclair and Diduck, 2005; Speer and Hughey, 1995). The final theme, local knowledge and memory, focuses on social learning and developing knowledge as a collective (Beilin and Wilkinson, 2015). These four underlying themes serve as useful starting points in understanding the different layers of resilience and determining how resilience thinking fits within multiple disciplines.

\section{B.3 Resilience in Urban Planning}

Resilience thinking has infiltrated a vast diversity of fields, gaining prevalence in the natural, physical, and social sciences. The concept's relevance and usefulness extends beyond ecology, engineering, and economics (Davoudi et al, 2017). Urban planning is no exception. Davoudi and Porter (Davoudi et al, 2012) argue that the planning community of practice, with a focus on innovation and continuously seeking to improve current circumstances, is quick to embrace new terms, concepts, and strategies such as resilience. In planning theory and practice, resilience is viewed and examined in terms of the relationships between humans and the environment (Mehmood, 2016). Yet, planners must extend beyond the blind acceptance of a term (Davoudi et al, 2012); they must dissect it, challenge it, and modify it, so that new concepts and approaches are well understood and effective in furthering practice. Urban planning plays a central role in achieving a resilient 
city; in ensuring that communities and the built form can confront and tolerate shocks and stresses.

The ideas underlying resilience thinking are not new to urban planning in Canada. In fact, the Canadian Institute of Planners (CIP) draws connections to many of the key themes of resilience in their Statement of Values. The first statement stresses the need for planners to consider intra- and inter-generational impacts, understanding that addressing short-term priorities can have ramifications for future generations. The CIP also acknowledges the need for planners to act as stewards of the environment and account for uncertainty through flexible and adaptable approaches (Canadian Institute of Planners, n.d.). The incorporation of resilience in urban planning can provide a welcomed perspective "breaking planning out of its obsession with order, certainty and stasis", confronting the "fundamental futility of preparing 'blueprint' type strategies", and ensuring entrenched linkages between social and ecological systems (Davoudi et al, 2012, p. 330). There remains a challenge, however, in interpreting planning using resilience thinking - in that, resilience is an ecological concept that is then transposed onto a socially constructed landscape. Scrutinizing power dynamics, the uneven allocation of and access to resources, and the political nature of human decision-making is necessary when approaching urban planning through the perspective of achieving resilience (Davoudi et al, 2012). While much of the thinking that comprises the foundation of resilience may already be present in the urban planning community of practice, effective incorporation of resilience strategies requires critical alignment with the multifaceted factors that confront urban planners.

\section{B.4 Defining Resilience for a Given Place}

Despite a general understanding and use of the term urban resilience, a "shared conceptual definition" is desired (Beilin and Wilkinson, 2015). As a large-scale, overarching perspective, the Rockefeller Foundation's definition of urban resilience could begin to address this gap in shared understanding through their far-reaching and influential network. Yet, it is also important to consider that resilience is a broad and allencompassing concept that cannot mean everything to everyone (Beilin and Wilkinson, 2015). In order for governing for urban resilience to yield systemic, enduring change, it is 
important to define resilience of "what" to "what"; the context-specific issues facing a given group of stakeholders in order to facilitate a shared understanding and common framework for action (Carpenter et al, 2001, p.765; Mehmood, 2016). In contrast to sustainability, resilience can be favourable or unfavourable. For instance, a system that negatively affects well being such as a corrupt government, insufficient water resources, or an authoritarian dictatorship could be resilient yet highly unfavourable. Sustainability, on the other hand, is an objective with underlying predispositions or expectations for favourable circumstances in a given system (Carpenter et al, 2001). As Davoudi et al (2012) states in reference to resilient approaches, "the emphasis is on the return to 'normal' without questioning what normality entails" (p. 302). It is necessary for residents, communities, and local governments to consider what 'normal' means in their city and whether it is worth maintaining.

Incorporating resiliency in planning practice requires flexibility, a focus on adaptive capacity, acknowledgement of the inevitability of uncertainties and change, continuous learning, awareness of the interconnected nature of socio-ecological systems, and collaboration at various scales. To achieve or enable resilience, it is useful to approach this "urban policy discourse" as both a "process of organized improvisation" and a crucial component in "collective, democratic, problem-solving" practices (Wagenaar and Wilkinson, 2015, p. 1265 and 1281). Given the ambiguous and contextual aspects of resilience, it is important for communities and local governments to define problems in their urban centre asking: What acute shocks and chronic stresses does their city experience? What does a 'resilient city' mean in their urban area? How can it be measured, observed, and sustained?

\section{B.5 Planning for Climate Resilience}

Before investigating the methods in which open data tools can be used to build urban climate resilience when faced with unprecedented and uncertain changes, it is important to consider the major effects that climate change will have on cities and to consider the role that urban planning and planners play. The impacts include sea level rise (e.g. storm surges) affecting coastal urban centres, public health repercussions arising from higher 
average temperatures and extreme weather events (e.g. vector borne disease, diseases from food and water, death, and sickness due to heat and cold), consequences for energy usage (e.g. for warming and cooling, energy required for water), diminishing access to water and resources, and the effects of extreme weather events on the built form (e.g. caused by droughts, heat waves, floods from major precipitation, storm surges, wind storms, etc.). A changing climate may also have consequences for tourism, cultural heritage, urban biodiversity, and air pollution (Hunt and Watkiss, 2011). As a result, climate change will impact the social, economic, and ecological systems that comprise a city, making brutally clear the interdependency between humans and the environment.

An understanding of the potential effects of climate change is imperative to safeguarding the future and developing a perception of risk. In stressing the importance of addressing global issues such as climate change at the local scale by the local government, Bai (2007) describes three major obstacles that hinder cities from accounting for global environmental concerns. The obstacles are distinguished by scale and include the spatial scale ("not on my turf"), the temporal scale ("not in my term"), and finally, the international scale ("not my business") (Bai, 2007, p.17, 19, 21). A prominent challenge in developing local scale strategies for climate change adaptation is the contradiction of short-term plans and the long-term threats of a changing climate (Wilson, 2006). Thus, it is useful to consider the cobenefits - such as greener healthier communities - that arise from taking action for mitigation and adaptation.

\section{B.6 Climate Action at the Local Scale}

While past trends in developing energy and climate policy have occurred on international and national scales, Allman et al (2004) stress that the local level is where initiatives for climate change mitigation and adaptation will be implemented. Robinson and Gore (2015) draw attention to the role of municipalities within the global reach of climate change, specifically how municipal initiatives fit within the bigger picture of climate change responses and if there is recursive influence of local action, stimulating larger scale planning that then spurs or enables smaller-scale activities. Scholars argue that climate change adaptation requires localized applied knowledge while mitigation is more of a 
global scientific undertaking (Evans, 2011; Ligeti et al, 2007). City level evaluations are imperative given their high population densities, prevalence of economic and social activity, and their capacity as centres of administrative governance. Further, it is necessary to undertake investigations at the urban level due to the differentiation of climate change impacts across cities as a result of microclimates and heat island effects (Hunt and Watkiss, 2011).

In order for local governments and corresponding stakeholders to address the impacts of climate change in their urban centres, an understanding or awareness of the contextspecific risk is imperative. City scale research is useful for determining early priorities for action that is economically rational, builds capacity, accounts for current climate variability, and emphasizes no regret procedures, all the while considering the crucial uncertainty of the nature and timing of climatic change (Hunt and Watkiss, 2011). In addition, developing local climate change scenarios can help to visualize and depict information that is meaningful and comprehensible to the general public (Sheppard et al, 2011). An assessment of the contextual impacts affecting a city coupled with the capacity of stakeholders to take action establishes what needs to be accomplished or overcome as well as what is feasible.

In the United Nations Framework Convention on Climate Change (UNFCCC) report detailing the agreement from the COP21 Paris Conference in 2015, Article 7 refers to adaptive capacity, resilience, and vulnerabilities. A work plan for 2016-2020 was launched with priorities to:

1. Indicate capacity gaps with recommendations on how to acknowledge them;

2. Promote the development and dissemination of tools and techniques for the enactment of capacity building; and

3. Stimulate dialogue, coordination, collaboration, and coherence within the Convention focusing on knowledge and information sharing (UNFCCC, 2016). This paper argues for the use of open data to further urban resilience discourse and programs, effectively contributing to priorities 2 and 3 of the UNFCCC Article 7 work plan, through the creation of tools and procedures that help build capacity, focus on information 
provision and data availability, and encourage communication and coordination among stakeholders.

\section{B.7 Introduction to Open Data}

Open data is an emergent, instrumental tool (Janssen et al, 2012) that is proving useful and valuable for a variety of priorities including transparency, accountability, engagement, and innovation (Open Knowledge International, n.d.). Open data, as defined through the open definition in the Open Knowledge International's Open Data Handbook, refers to, "data that can be freely used, reused and redistributed by anyone - subject only, at most, to the requirement to attribute and share alike" (Open Knowledge International, n.d., p.3).

Open data initiatives must account for prominent barriers (e.g., insufficient knowledge of citizens to use or understand the data and deficient tooling support or metadata) in order to take advantage of meaningful benefits (e.g., self-empowerment of citizens and enhancement of policy-making procedures) (Dawes, 2010; Janssen, 2012). Sieber and Johnson (2015) outline seven obstacles governments face when publishing open data. They are: "access", "governance" (e.g. understanding among the public, lack of clarity in policy regarding open data), "costs" (e.g. infrastructure needed for data provision such as open data portals), "data” (e.g. interoperability of data, need for complete and accurate information), "legal" (e.g. concerns around ownership, privacy, and confidentiality), "metadata" (e.g. explanations behind the data, comparable formats), and "skills" (e.g. users' abilities to employ the data, confusion around data, and digital divide) (Sieber and Johnson, 2015, p.313). More and more cities, regions, and countries are releasing data to be used and reused through portals and catalogues, allowing for the creation of products and services by the public, private, and third sectors that address pertinent public needs. When considering the potential for open data to contribute to complex problems such as climate change, it is essential to consider the obstacles at play and how they can be confronted in order to incorporate open data in robust, lasting solutions.

\section{B.8 Open Data for Urban Resilience}

Resilience is a problem-solving process that requires collaboration from a wide array of stakeholders in a proactive, evidence-based, and holistic manner. As such, open data 
provides a number of opportunities for the urban resilience community of practice. Open data tools have the capacity to provide real-time contextual data to contribute to solutions for health, transportation, and agriculture issues; foster engagement, collaboration, and non-governmental problem-solving; and even instigate a new form of policy- and decisionmaking (Bertot et al, 2014). According to Sieber and Johnson (2015), the open data community of practice is at a "crossroads between competing initiatives"; on the one side, there are opportunities to meet economic priorities and foster innovation and on the other side, there is a push for enhanced openness, reliability, and civic engagement (p.312). The path that governments choose at this crossroads, navigating opportunities for innovative research and development, crowdsourcing, and resident inclusion, will ultimately determine the interactions between government and residents and the adoption of open data (Sieber and Johnson, 2015).

The seven obstacle categories listed above are necessary considerations for local governments in releasing open and big data. In considering open data tools through the lens of urban climate resilience, these obstacles could provide challenges for open data initiatives that are either government-led, top-down or grassroots-based, bottom-up. The 'skills' obstacles may arise, for instance, when using open data to foster coordination and communication among residents or disseminate vital information pre- or post-disaster. Dawes (2010) notes that the misuse or misunderstanding of open data generally occurs when data is utilized to satisfy an objective that was not what it was collected for or how it was intended to be used. Robust metadata and user-friendly data infrastructure that provides information beyond machine-readable, spatial, "low hanging fruit" data (Sieber and Johnson, 2015, p.313), and allows for two-way communication and feedback, may be laborious and complex but are crucial in realizing open data tools as a key component of social learning, transparency, and collaboration among stakeholders (Janssen et al, 2012). The effectiveness of open data tools depends on the ability of data providers to address these challenges such as complete data, clear policy, and effective communication platforms. 
The intersection of open data tools to inform urban resilience discourse and strategy is very much in the initial stages of research and implementation (Landry et al, 2016). The work of Bloomberg Philanthropies is active in both communities of practice which offers a potential opportunity in facilitating integration moving forward. As UN Special Envoy for Cities and Climate Change, Michael Bloomberg plays a prominent role in helping cities act on climate change - mitigating emissions and strengthening their resilience to extreme weather events (Bloomberg Philanthropies, 2017b). Bloomberg Philanthropies also established the What Works Cities Initiative in 2015, aiming to guide American cities in improved usage of data (preferably open) and evidence-based methodologies to enhance service provision, planning, and decision-making (Bloomberg Philanthropies, 2017a). Explicit and clear convergence of initiatives such as Bloomberg's programs for Sustainable Cities and What Works Cities could demonstrate the use of open data tools in advancing urban climate resilience.

Initiatives such as Open Cities and the Open Data for Resilience Initiative, while differing in scale, draw parallels in prioritizing accountability, innovation, and experimentation, and provide insights into the integration of open data in the realm of resilience planning and disaster risk management. The Global Facility for Disaster Reduction and Recovery (GFDRR) established the Open Data for Resilience Initiative to address disaster planning and risk management at the national scale. The Open Data for Resilience Initiative serves as an example of bridging the gap between the two communities of practice: open data and resilience. The GFDRR stresses that in order "to alter the mental models of risk across a whole population", data availability and the skills to process and employ the data are paramount (GFDRR, 2014, p. 2). Further, effective disaster risk management and planning hinge upon awareness and measures for the collection, construction, and assessment of data related to the risks and uncertainties affecting built form and urban centres in the future. The Open Data for Resilience Initiative is a national scale strategy with the objective to foster a "living data ecosystem" where data provision is open both legally and technically, and local situations, risks, and vulnerabilities are incorporated for climate action (GFDRR, 2014, p.21). Large-scale and far-reaching initiatives such as Open Data for Resilience and Open Cities are broad and prominent efforts to merge the open data and 
resilience communities of practice. In order for a resilience-based framework to truly become cemented in urban planning, diverse, on the ground examples are useful to provoke thought, allowing practitioners to consider how such programs and projects are initiated, what they involve, and whether they are effective.

\section{B.9 Exploration of International Use Cases}

The international use cases which form the basis for this research study are investigated through the lens of five themes, informed by literature, that explore the integration of open data tools in urban resilience. The five themes are:

1. Open data to yield insight on vulnerabilities associated with the shocks and stresses of climate resilience;

2. Considerations for government-led and community-led initiatives;

3. Proactive versus reactive approaches;

4. Fostering community mobilization and collective action through the employment of open data in urban climate resilience strategies; and

5. The interaction between mitigation and adaptation for climate action exploring how open data fits within these two distinct yet complementary strategies.

B.9.1 Open data to help inform and act on vulnerabilities associated with shocks and stresses of climate resilience A prominent component of governing for resilience, when faced with an unprecedented changing climate, is determining the vulnerabilities that exist within a city. Beilin and Wilkinson (2015) argue that acknowledging vulnerability is not a weakness but rather can serve to establish a connection among people. In exploring the Swedish context for climate change adaptation planning, Betsill and Bulkeley (2007) found that there were barriers resulting from inadequate technical information about vulnerabilities. Another research study in Europe found that the needs and requests related to adaptation planning and the creation of decision support systems were not sufficiently depicted or understood. Often, the research demands of policy- and decision-makers are listed in a general, sweeping manner such as "more vulnerability assessments" or "more socio-economic implications of adaptation" (Hanger et al, 2013, p.99). General statements indicating the need for vulnerability assessments are a starting point, yet specific understanding of what makes a 
city vulnerable is key to building resilience; considering the wide range of factors that influence vulnerability such as socioeconomic status, geography, housing type, and provision of services.

Open data can contribute to determining vulnerabilities to climate change within a city through strategies that focus on the spatial aspect of vulnerability, exploring where vulnerable communities, infrastructure, and individuals are located. Mapping initiatives yield opportunities for knowledge sharing, informed decision-making, and open innovation for those initiatives that involve a wider group of stakeholders (GFDRR, 2014). According to Junar, a global open data platform company, mapping and GIS data comprise the second most popular datasets accessed; environmental and sustainability data ranks 10th (Shueh, 2015). GIS data is widely available on open data portals enabling the mapping of vulnerabilities.

Open sensor and real-time data are also useful for determining vulnerabilities within a city as they provide detailed, dynamic information exploring environmental conditions (e.g. pollution, humidity, $\mathrm{CO} 2$ emissions) in specific areas that can then help inform strategies for public health, energy management, etc. Data that can be linked or combined is especially favourable to add layers to the analysis (Domingo et al, 2013). It is important, however, to acknowledge the processing challenges and added technical necessities that can arise when collecting and using real-time data (Headd, 2014). Other advanced characteristics embedded in the functioning of open data portals can serve to provide, display, and help interpret information on vulnerabilities such as collaborative filtering, crowdsourced data collection and processing, discussion forums or wikis, and visualization mechanisms to help identify patterns in the data (Robinson et al, 2010). These advanced characteristics serve to aid stakeholders in the civic technology and open data community of practice and can also involve and even benefit citizens, more broadly, providing additional opportunities for two-way communication.

Open data can also provide insight into how vulnerabilities are perceived and how to anticipate future vulnerabilities given historical progressions and patterns through 
predictive analytics and data mining. Predictive analytics investigates past trends and frames of reference to yield insight into expectations for the future, into changes in the provision of services, and to circumvent or impede possible challenges. The success of predictive analytics as a tool for critical analysis, anticipatory planning, and problem solving depends upon governments' willingness to be open in their information sharing and coordination (Goldsmith, 2016). The City of Chicago recently launched Array of Things, a sensor-based project for the urban area that uses nodes throughout the city to collect data on subjects such as climate, traffic, air pollution, etc. The tool assists in developing a deeper understanding of the pertinent challenges faced in the city such as evaluating the extent and repercussions of climate change. The Array of Things project supports the predictive analytics conducted by the City of Chicago (Mitchum, 2016). For instance, the City can better respond and prepare for floods in particularly flood-prone areas through the weather information collected by the sensors.

Data mining is another strategy that uses open data to unearth information regarding the vulnerabilities and risks that makeup a city. Data mining, in a general sense, refers to "the process of discovering interesting patterns and knowledge from large amounts of data" (Han et al, 2012, p.8). Lausch et al (2015) claim that data mining processes that use linked open data can contribute new findings for elaborate and multi-disciplinary issues and intricate environmental challenges or considerations. In their paper, Unveiling hidden migration and mobility patterns in climate stressed regions: A longitudinal study of six million anonymous mobile phone users in Bangladesh, Lu et al (2016) used mobile phone data to explore the mobility and migration trends in the midst of and following an extreme weather event. Social media mining can also contribute useful information in terms of public opinion and interpretations of climate change provided data collection and access is possible (Kirilenko and Stepchenkova, 2014). Data mining, real-time sensor data, and predictive analytics, as well as other open data tools are useful in illustrating urban circumstances in a coherent manner. These tools can contribute insight into understanding the various threats or limitations faced in a city ranging from physical infrastructure deficiency to income inequality to environmentally sensitive areas. When coupled with 
resilience strategies led by communities or governments, open data tools can provide the evidence needed to strengthen an urban centre and better prepare for future risks.

\section{B.9.2 Considerations for Government-led and Community-led initiatives}

In building resilient cities, there are opportunities for top-down, government led approaches, bottom-up, grassroots or community-led approaches, and hybrid operations that involve collaboration between the two (Beilin and Wilkinson, 2015). In considering the organization and foundation of climate action strategies, this theme considers the efficiency of the process and the goals and priorities of both bottom-up and top-down initiatives. In the contribution of Working Group 2 to the Fifth Assessment report of the Intergovernmental Panel on Climate Change, Field et al (2014) found with medium confidence that adaptive capacity of local governments and communities is one of several factors that advances urban climate change adaptation. Both governments and communities have a role to play in climate action.

Scholars have identified gaps in the literature on mitigation and adaptation endeavours in which initiatives that could be perceived as bottom-up or community-led are often neglected from the discourse on climate action. Broto and Bulkeley (2013) found that the literature neglected the diversity of climate change action strategies that are evolving beyond formal decision-making and involving stakeholders apart from municipal governments. Further, Robinson and Gore (2015) determined that the projects or strategies outside or in between the formal monitoring and reporting of milestones, such as the ICLEI and BARC program for climate adaptation and resilience, require recognition for both pragmatic and theoretical rationales. A lack of incorporation of all of the climate action strategies that exist hinders the comprehensive nature of a review; limiting the scope of understanding what is already in progress and what is possible (Robinson and Gore, 2015).

There are opportunities and challenges to both government-led and community-led initiatives. Despite only contributing less than $3 \%$ of total emissions, the public sector has a unique perspective and ability to offer guidance and advice to other sectors (Allman et al, 
2004). In their study, The progress of English and Welsh local authorities in addressing climate change, Allman et al (2004) found that there were two main distinctions between the local authorities that had effective measures and those that did not. The distinctions were support for funding and guidance from internal and external sources and collaboration with other departments, regional authorities, and public sector organizations. The study also noted the following barriers for local authorities in realizing climate action: 1) alternative concerns take priority in terms of time and energy; and 2) challenges in organizing a regional strategy (Allman et al, 2004). Governments are faced with competing pressures further impeded by the often distant and uncertain effects of a changing climate.

Through the lens of open data, bottom-up, community-led approaches to climate resilience could involve crowdsourcing or citizen science techniques. Top-down, government-led approaches might focus more on open government principles such as, accountability, transparency, and standardization (Bertot et al, 2014), and the use of measurement or performance indicators. In releasing data that is open and freely available for reuse, governments are, essentially, relinquishing some of their control (Janssen et al, 2012). In doing so, they allow for the use of the data by a wider variety of users for the creation of products and services - an arrangement or exchange that is all the more fruitful when governments are receptive to critical feedback and inputs (Longo, 2011; Janssen et al, 2012). When data is released or 'opened', there are opportunities for more people to view the data, and thus pinpoint extraneous components, opportunities for crowdsourcing, and public contribution to strategies for improved data management (Fox and Pettit, 2015). Crowdsourcing of data from residents can enable enhanced civic engagement ( $\mathrm{Nam}, 2012$ ) strengthening the interactions between government and citizen - overlapping with the fourth theme framing this analysis: Community Mobilization and Collective Action.

Considering the current crossroads that practitioners face in using civic open data juggling opportunities of engagement, economic innovation, crowd sourcing, and policymaking, Sieber and Johnson (2015) describe four distinct, non-consecutive models that can occur during the preliminary phases of adopting open data initiatives. They are: 1) "A status quo 'data over the wall' form of government data publishing"; 2) "Code exchange: 
with government acting as open data activist or application development sponsor"; 3) "Open data as a civic issue tracker; government as civic issue tracking and sensing"; and 4) "Participatory open data" (Sieber and Johnson, 2015, p.310-311). While all four models could contribute to the development of bottom-up open data initiatives, the third and fourth models explicitly explore the provision of data by the public. The third model, "Open data as a civic issue tracker", incorporates data created through crowdsourcing - "where a collective of individuals with little formal coordination, contribute towards a shared goal or cause, in this case, improved government services and infrastructure" - in addition to data created by the government (Sieber and Johnson, 2015, p.311). SeeClickFix, Open311, and FixMyStreet are examples of initiatives that fall within this model whereby the government facilitates the involvement of citizens in data provision - recognizing the ability for these measures to improve civic engagement while also allowing governments to benefit from "citizen sensors" (Sieber and Johnson, 2015, p.311). In the fourth model, "Participatory open data", residents are included through data creation and requesting data provision and release from the government. Open data becomes part of a process of co-creation and collaborative review and revision. In this model, the use of open data advances policy formation and the development of further programs and strategies in addition to the creation of products and services by the private sector (Sieber and Johnson, 2015). These two models illustrate the creation of open data or the adoption of open data by both the government and the public yielding opportunities for co-production and collaboration.

When considering top-down, government-led or inside government open data initiatives that build urban resilience to climate change, interoperability, standardization, and reliability are factors for consideration. There is a push for open data to be interoperable whereby it can be reused, machine-read, and linked to other datasets. Zuiderwijk and Janssen (2014) outline pertinent components to include in the development of an open data policy structure. In addition to interoperability, they highlight the need to consider the quality, reliability, and validity of the data including whether it is up to date and detailed (Zuiderwijk and Janssen, 2014). They also note the need for a "standard format" with clear definitions, consistency of sources, a level of blending of the sources, and regularity in how various departments release open data (Zuiderwijk and Janssen, 2014, p.19). In 
incorporating these characteristics, open data policy enables straightforward access, reliable comparison, and fruitful analysis.

The International Organization for Standardization has developed the ISO 37120, a set of indicators with corresponding explanations and methodologies, to be used by cities to evaluate their services and quality of life as part of sustainable development strategies. IS0 37120 was developed to confront challenges pertaining to the comparability and coherence of most city measurements. The ISO 37120 incorporates indicators across a wide variety of themes including urban planning, environment, fire and emergency response, and water and sanitation. The indicators are quantitative, qualitative, and descriptive; yet, allow cities to determine their own targets and benchmarking goals (ISO, n.d.). ISO 37120 is useful in evaluating performance, informing policy decisions, administering services, and providing cities with "a reliable foundation of globally standardized data" that facilitates "comparative insight and global benchmarking" (ISO, n.d. p.2). ISO 37101, developed in 2016, outlines the essential components of a "management system for sustainable development" with the explicit goal for the ISO 37101 to be employed to assist communities in developing resilient, smart, and sustainable initiatives, programs, and plans (ISO/TC 268, 2016, para 1). The World Council on City Data is a global organization that assists a network of cities in implementing the ISO 37120 standard. They strive to realize "smart, sustainable, resilient, and prosperous" urban areas (WCCD, n.d., para 1).

The development of standard city indicators such as ISO 37120 allows cities to measure their performance in a repeatable and consistent manner. It also can incorporate open data through the publishing of the city indicator results and the corresponding data or information used to determine the indicator. In their paper, On the Completeness of Open City Data for Measuring City Indicators, Fox and Pettit (2015) propose a method, called the City Indicator Data Openness Measure, which evaluates the "degree of openness of a city indicator" including the indicator result and the corresponding data used in the calculations (p.2). While a standard series of indicators that can be used over time and across cities is a significant step for widespread transparent and accountable government- 
led open data initiatives, the release of corresponding data used to calculate the indicator is necessary in order to truly evaluate performance openly and collectively comprehend what the indicators mean for urban resilience (Fox and Pettit, 2015). There is not always an exact, clear distinction between bottom-up, community-led and top-down, government-led strategies that utilize open data to advance the resilience of a city. Understanding the inception of a strategy, program, or project, including the actors and priorities, sheds light on the scope, applicability, and reasoning of a given initiative.

\section{B.9.3 Proactive versus reactive approaches}

The third theme considers the difference in priorities and parameters for strategies that are proactive or pre-disaster and those that are reactive or post-disaster. Interventions for climate change adaptation, for instance, can be proactive or reactive; pertaining to protection (e.g. vulnerability assessment, capacity building, and risk reduction measures); pre-disaster damage limitation (e.g. early-warning systems, community-based disaster preparedness, and response plans); immediate post-disaster responses (rapid infrastructure restoration); and rebuilding (Broto and Bulkeley, 2013). For the purpose of this research, proactive strategies acknowledge the certainty of change and the need for rearrangements that are pre-emptive and anticipatory (Caputo et al, 2015). Proactive strategies for climate resilience draw on the evolutionary concept of resilience, are often experimental, and have a systems-based approach. Reactive strategies, on the other hand, have an issue-based approach, focused on fixing a problem that has manifested.

Whether strategies for climate change planning take on a proactive or reactive approach largely depends on the priorities and perspectives of governments or related communities of practice. How do perceived risks, prioritization, and the urgency of threats contribute to the launching of a proactive strategy versus a reactive strategy? Gruber et al (2015) note that initiatives for climate change adaptation are challenged by the discounting of events or impacts distanced by space or time, the probability and uncertainty of impacts, and the lack of resources and capacity to create effective action plans. In terms of prioritizing climate action, local officials often feel incentivized to adopt initiatives on adaptation and mitigation when they realize it can contribute to the city's financial savings and urban 
planning and design, while enhancing well-being for residents (Bai, 2007). Further research on the potential for circumstances to yield strategies or initiatives that are simultaneously proactive and reactive would complement this research and provide insight into the associated implications on climate change planning.

Open data can play a role in both proactive and reactive initiatives. Government provision of data and sponsorship of application creation can help to facilitate proactive strategies through encouraging the use of data to create innovative and valuable products and services (Sieber and Johnson, 2015). Research has found that emerging digital technologies can realize decisions that policy officials could not have forecasted when first creating the technology (Sieber and Johnson, 2015). In releasing data that is comparable, robust, and interoperable, governments can enable the creation of applications, products, and strategies that address issues as they occur and also work towards preventing or anticipating future threats and challenges.

\section{B.9.4 Community mobilization and collective action}

Building a city that is resilient requires adaptive capacities of both the government and communities, communication across scales, and collaborative problem solving (Beilin and Wilkinson, 2015; Caputo et al, 2015). Public engagement is a crucial component of climate change planning allowing for plans and action to account for and encompass local knowledge, perspectives, attitudes and values (Gruber et al, 2015; Wolf and Moser, 2011). Gruber et al (2015) determined that participatory processes and attention to transparency are imperative for the legitimacy of an adaptation initiative. Unrealistic expectations emerge when there is a depreciation or misunderstanding of adaptation being an intricate social process (Field et al, 2014). Individuals are pivotal in the reduction of greenhouse gases and developing adaptable infrastructure and policy. As such, effective action rests on the understanding of their "cognitive and emotional engagement", how engagement is influenced by attitudinal transformations, and what results from that engagement (Wolf and Moser, 2011, p.547). 
Climate change is an unprecedented, collective issue that requires a systemic and profound societal paradigm shift (UNDP, 2007; Dale et al, 2012). As a result, community members must be engaged with and take ownership of the issues and their solutions. Of particular importance are citizens' social capital and in turn, their agency, referring to a person's ability to respond to issues and instigate change (Newman and Dale, 2005). Further, a community's investment in a plan is guided by their degree of influence, attachment and dedication to their environment, and engagement between diverse stakeholders (Tippet et al, 2007; Innes, 1995; Manzo and Perkins, 2006). Partnerships and collaborative practices play a pertinent role in strengthening capacity and realizing consensus (Broto and Bulkeley, 2013). If climate change adaptation is not approached as an issue requiring collaboration, dialogue, and collective responsibility (UNFCCC, 2016), then a profound shift in practices and behaviour is not possible (Dale et al, 2012).

Effective citizen engagement relies upon an understanding of the power dynamics in a context (Flyvbjerg, 1998). Drawing on Foucault, Flyvbjerg emphasizes the dependency of rationality and knowledge on power (Flyvbjerg, 2002). Thus, power determines the information withheld and disclosed, the framing of an issue, and the intensity of public involvement (Miller, 2008; Sinclair and Diduck, 2005; Speer and Hughey, 1995). The uneven extent of power and manipulation among stakeholders that drives planning and decision-making must be encountered and reconciled so that citizens have agency in shaping the future of their communities (Sager, 2002; Few et al, 2007).

Urban planning is a critical intermediary enabling civic engagement in government climate resilience. While scholars stress the necessity of public contribution, in practice there is little action to measure the extent to which meaningful community involvement occurs in climate change adaptation (Collins and Ison, 2009). Social learning provides a useful evaluation framework here with its focus on cooperation among stakeholders who learn by doing, leading to shared understandings and collective action (Collins and Ison, 2009; Manzo and Perkins, 2006; Innes, 1995). Cultivating social learning and collaboration among diverse stakeholders requires tools and techniques for capacity building and empowerment to mobilize individuals and foster dialogue. 
Open data has a meaningful role to play in engaging and mobilizing communities to take collective action on climate change. For instance, the inclusion of data and scientific information strengthens the ability for engagement and learning when visualizing potential climate change impacts (Sheppard et al, 2011). Open data tools have the ability to strengthen participation, communication, social inclusion, and self-empowerment (Zuiderwijk and Janssen, 2014). As opposed to theme 2, Considerations for government-led and community-led initiatives, theme 4, Community mobilization and collective action, refers to the outcome of the initiative as opposed to the inception of the process exploring what the initiative instigated or encouraged rather than how the initiative was created.

Supporters of open data assert it can be instrumental in achieving ubiquitous engagement, referring to "democratic literacy" and the significant involvement of public residents in governance processes (Roy, 2014, p.420). Governments identify civic hackathons as an engagement strategy as it is a participatory event and drives the development of products and services (e.g. mobile and web-based applications), which are intended for public use. As opposed to entrepreneurial app contests, civic hackathons are based on the use of government open data, are coordinated by a government agency, and aim to develop products and services that address needs of the public (Johnson and Robinson, 2014). Civic hackathons can also inform municipal government officials about opportunities or challenges in using government open data, allowing for suggestions about what can be altered or revised in the future. In this capacity, civic hackathon participants are "sensors", yielding information and critiques about the open datasets to "government data custodians" (Robinson and Johnson, 2016, p.66). Hackathons, thus, have the potential to facilitate two-way communication between government and participants, ideally engaging and mobilizing participants while advising government officials.

There are, however, certain challenges that open data strategies must overcome in order to advance collective action and collaborative practices in governing for resilience. If open data portals or the medium for accessing data has a complicated and confusing interface or set of operations, then initiatives are in danger of perpetuating social inequalities and 
dissuading communities as opposed to enhancing transparency and citizen collaboration (Nam, 2012). The digital divide and differences in access or skill abilities can also challenge citizen involvement (Belanger and Carter, 2009). Metadata plays a prominent role in the provision of coherent and clear open data. Certain levels of knowledge and expertise in technology, statistical skills, and analysis of large quantities of data are required to effectively use most open datasets. Lack of time, incentives, clarity, and relevance can deter residents and hinder community mobilization (Janssen et al, 2012). Community involvement and collective deliberation and action hinges upon residents' willingness and commitment to participating.

Recognizing the challenges which limit resident involvement and collaborative action, open data policies must stress the need for up to date and reliable data, accessibility, a consistent and standard setup, and policy tools that value a consensus-based process considering incentives and multifaceted mechanisms (Zuiderwijk and Janssen, 2014). Feedback mechanisms and data visualizations are useful to bridging the gap between accessing and actually understanding or using the data. Addressing the need for a system to assist users in interpreting the data will help transform open data initiatives to act as consistent form of communication between governments and citizens, benefiting from shared learning and collective intelligence (Janssen et al, 2012). In terms of urban climate resilience, this form of communication through the deployment of open data tools can then be employed to take collaborative action.

\section{B.9.5 Mitigation and Adaptation}

The final theme recognizes that climate resilience requires both climate change mitigation and adaptation approaches. In their paper, Looking back and thinking ahead: a decade of cities and climate change research, Betsill and Bulkeley (2007) identify a deficiency in academic research on climate change adaptation. Further, in a more recent study surveying urban climate change experiments in 100 cities, only $12.1 \%$ of experiments were related to climate change adaptation (Broto and Bulkeley, 2013). The federal report, From Impacts to Adaptation: Canada in a changing climate, stresses the need to address barriers to adaptation calling attention to the significant limitations of awareness and access to 
information and tools (Williams, 2009). Scholars argue that climate change adaptation demands localized, applied knowledge and as such, the benefits are concentrated in the regions where the costs are absorbed. In contrast, mitigation is viewed as more of an international, scientific undertaking where benefits are enjoyed globally (Evans, 2011; Ligeti et al, 2007). As a result, while mitigation is an issue more opportune for provincial, federal, and international levels of government, adaptation is very much a local scale priority (Ligeti et al, 2007). The local and global characteristics of mitigation and adaptation yield insight into the cross-scale linkages of climate change as well as the initiatives that are more likely to take precedence at the urban scale.

In reviewing urban climate change experiments in 100 cities, Broto and Bulkeley explored adaptation experiments such as flood management, blue-green infrastructure, building codes that account for extreme weather events, prompt warming procedures, and initiatives for ensuring stable energy and water supplies. The mitigation experiments were investigated through 5 sectors including carbon sequestration (e.g. protection and rehabilitation of carbon sinks), built environment (e.g. energy-efficient equipment and design), urban form (e.g. brownfield revitalization), etc. (Broto and Bulkeley, 2013). Despite a growing prevalence of climate action initiatives at the local or municipal scale, there are limited measures on their influence or adequacy (Bulkeley, 2010). There are also limited methods for interpreting and confronting the intricate interactions arising from increased mitigation and adaptation endeavours such as connections between water, energy, land use, and biodiversity (Field et al, 2014). There is an opportunity for open data tools to fill the gap in measures for interconnectivity and success.

Mitigation and adaptation are inherently interconnected and thus it is important to strive for an integrated approach, considering how strategies for either priority influence or contribute to strategies for the other priority (Howard, 2009). As vehemently stressed by Howard, "for theoretical, moral, and thoroughly practical reasons", mitigation is "the most fundamental and urgent form of climate change adaptation" (Howard, 2009, p.20). This fifth and final theme considers the role of open data in mitigation and adaptation initiatives, more directly, how open data can contribute to integrated approaches in cities 
and "the spaces in between", as explored by Robinson and Gore (2015) - the climate action programs or initiatives at various scales and among various actors that fall outside formal milestone systems for monitoring and reporting.

These themes explore the merging of open data and urban resilience through the different lenses of 1) risk and vulnerability assessment; 2) the inception of initiatives; 3) diverging approaches to preparedness; 4) civic engagement and motivating communities to act; and 5) linkages between mitigation and adaptation strategies. This exploration of scholarly work delves into the two communities of practice: building resilience and employing open data tools - presenting challenges and opportunities for each. An understanding of the potential and limitations of both resilience thinking and open data tools is crucial to considering and experimenting with their integration in an effort to achieve flexible and dynamic cities in a changing climate. 


\section{METHODOLOGY}

This paper uses an exploratory research process that employs secondary data to investigate the role of open data in building urban climate resilience, answering the question, how can open data tools and techniques be integrated within climate change planning to build urban resilience and instigate a sense of agency and collective action among stakeholders? Stebbins (2001) defines social science exploration as,

"a broad-ranging, purposive, systematic, prearranged undertaking designed to maximize the discovery of generalizations leading to description and understanding of an area of social or psychological life" (p.3).

Secondary data constitutes the contents of the literature review, informing the themes of investigation, as well as the use cases.

Exploration is a process that often takes place among several studies (Stebbins, 2001). As such, this exploratory study builds upon a recent paper titled, How can we improve urban resilience with open data?, developed by Open North for the United Kingdom Open Data Institute (Landry et al, 2016). The paper - co-authored by Jean-Noé Landry, myself, Bianca Wylie, and Pamela Robinson - proposes five recommendations that begin to answer the question framed in the paper's title. The recommendations, developed through interviews with 36 international experts in the open data and resilience communities of practice, are as follows:

1. "Couple open data and urban resilience efforts to build a culture of openness"

2. "Assess and address similarities and differences in urban resilience work between low- and high-income countries globally"

3. "Close the open data capacity gap"

4. "Develop an agile approach to managing urban resilience"

5. "Cultivate business opportunities that address urban resilience issues" (Landry et al, 2016, p.9)

With these recommendations in mind, my research paper turns to the potential for open data to be used as a tool to govern for urban climate resilience, more directly, investigating what international use cases exist that begin to merge the open data and urban climate resilience communities of practice. 
The international use cases examined in this research study emerged from an environmental scan published in the paper, How can we improve urban resilience with open data? (Landry et al, 2016). Appendix A (p.41) of the Landry et al paper (2016) outlines use cases that emerged from the primary interview research. There are 92 use cases that are organized into 7 categories: Housing, Physical Infrastructure, Social Infrastructure, Climate/Environment, Health/Aging Populations, Networks/Community, and Economic Development. There are three criteria that form the basis for the selection of the international use cases explored in this paper that were identified from the list of 92 use cases (Figure 1). Relevant use cases required the following inclusion criteria:

- An initiative that engages stakeholders to use open data (e.g. civic hackathon, app contest, or a policy-making strategy) (Johnson and Robinson, 2014).

- The initiative must contribute to building climate resilience in urban areas.

- The initiative has concrete results, impacts, or outcomes (e.g. an app was created or policy was modified and implemented). For instance, in 2012, the City of Vancouver as part of their Greenest City 2020 Action Plan proposed opening the greenest city data as part of the City's Open Data Initiative to engage citizens in accomplishing the lighter ecological footprint goal (City of Vancouver, 2012). While not included in the Appendix list in the Landry et al paper (2016), in order for this initiative to be considered for the use cases, the initiative must have outcomes or results (e.g. citizens have used the greenest city open data or opening the data has assisted in achieving the objectives outlined in the lighter ecological footprint goal).

There is one additional use case incorporated in this research study that did not emerge from the environmental scan in the Landry et al paper (2016). The use case on the Deltares ID CIrcle tool (see Analysis section D.1.2) surfaced through field research I conducted in the Netherlands for a graduate project exploring blue-green infrastructure and planning for climate resilience. This paper recognizes that the use cases investigated may not include all the potential use cases that exist globally. Due to the scope of the paper, the research relies on the assumption that the use cases, originally gathered through international interview research and field research, offer a broad overview and representative insight of the initiatives or strategies that incorporate open data in building urban climate resilience. A list of the 17 use cases examined for this research is outlined in Appendix A. 
Exploration is undertaken when there is "little or no scientific knowledge about the group process, activity or situation" to be investigated, yet, the researcher has "reason to believe it contains elements worth discovering" (Stebbins, 2001, p.6). As mentioned in the literature review, there is currently limited research that explores the intersection of open data and urban resilience. This paper identifies five themes that speak to the relationship between open data tools and climate resilience, exploring the opportunities and challenges that arise from collaboration between the two communities of practice. The five themes that form the basis for the examination of the international use cases were informed by the literature review which incorporated more than 100 peer-reviewed, government, and grey literature sources. The literature reviewed fall within the topics of urban planning, climate change, resilience, open data, civic technology, and civic engagement. The papers were then organized into sub-themes such as Data and Governance, Civic Engagement and Climate Change, and Assessment of Open Data, to help organize the research and identify commonalities, integrative elements, and differences.

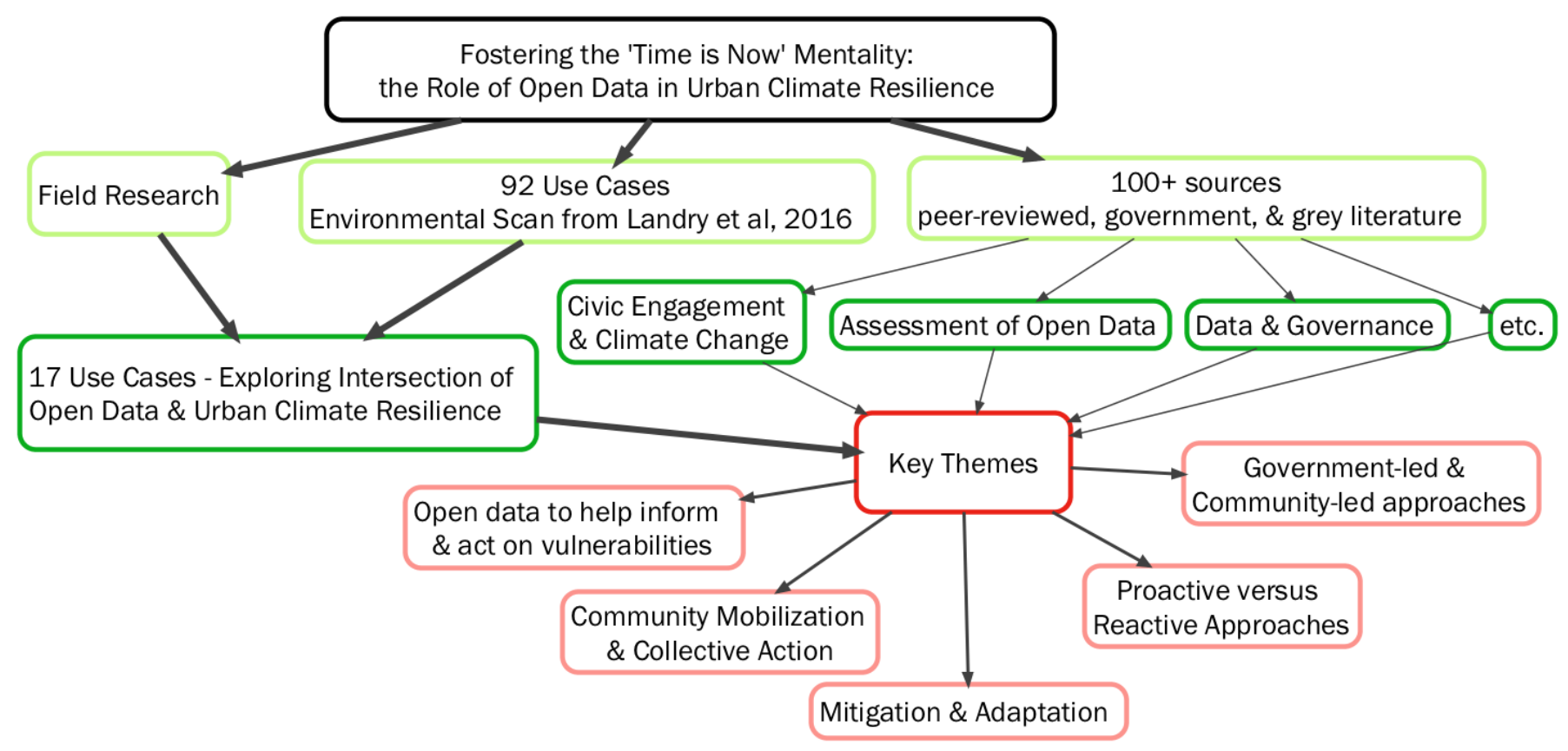

Figure 1: Exploratory research process examining the role of open data in building urban climate resilience 
The primary objective of exploratory research "is the production of inductively derived generalizations about the group, process, activity, or situation under study" (Stebbins, 2001, p.6). In merging literature and practical use cases, this paper aims to provide concrete examples of the integration of open data in urban climate resilience initiatives highlighting key considerations and future forward provocations. The exploratory research process for this paper is rooted in the understanding that "exploration and inductive reasoning are important in science in part because deductive logic alone can never uncover new ideas and operations" (Stebbins, 2001, p.8). 


\section{ANALYSIS}

The following analysis illustrates exemplary practice across the five themes, providing one to three key examples of open data tools or strategies that have been used to build urban resilience to climate change (Figure 2). Although open data catalogues and portals exist and can play a prominent role in the realm of climate change planning and decision-making, the examples highlighted for each theme extend beyond open data portals or 'low hanging fruit'. For instance, the Climate Change Knowledge Portal, developed by the World Bank Group, or the CDP Open Data portal provide data on climate change and associated risks and factors. Yet, these are excluded from this analysis as this section aims to highlight instances or initiatives where data, potentially from these portals, is used to realize specific outcomes or achieve objectives that build climate resilience in cities. This is made clear in the third criterion for the selection exploration of the use cases: the initiative must have concrete results, impacts, or outcomes such that the use of open data resulted in the creation of a product or service that contributes to the building of a resilient city. This portion of the paper presents eight of the 17 use cases interpreted in relation to the specific themes. The analysis indicates opportunities and challenges that arose from the development of the initiatives and intends to draw insights that can stimulate future dialogue and action regarding the integration of open data and urban climate resilience. 


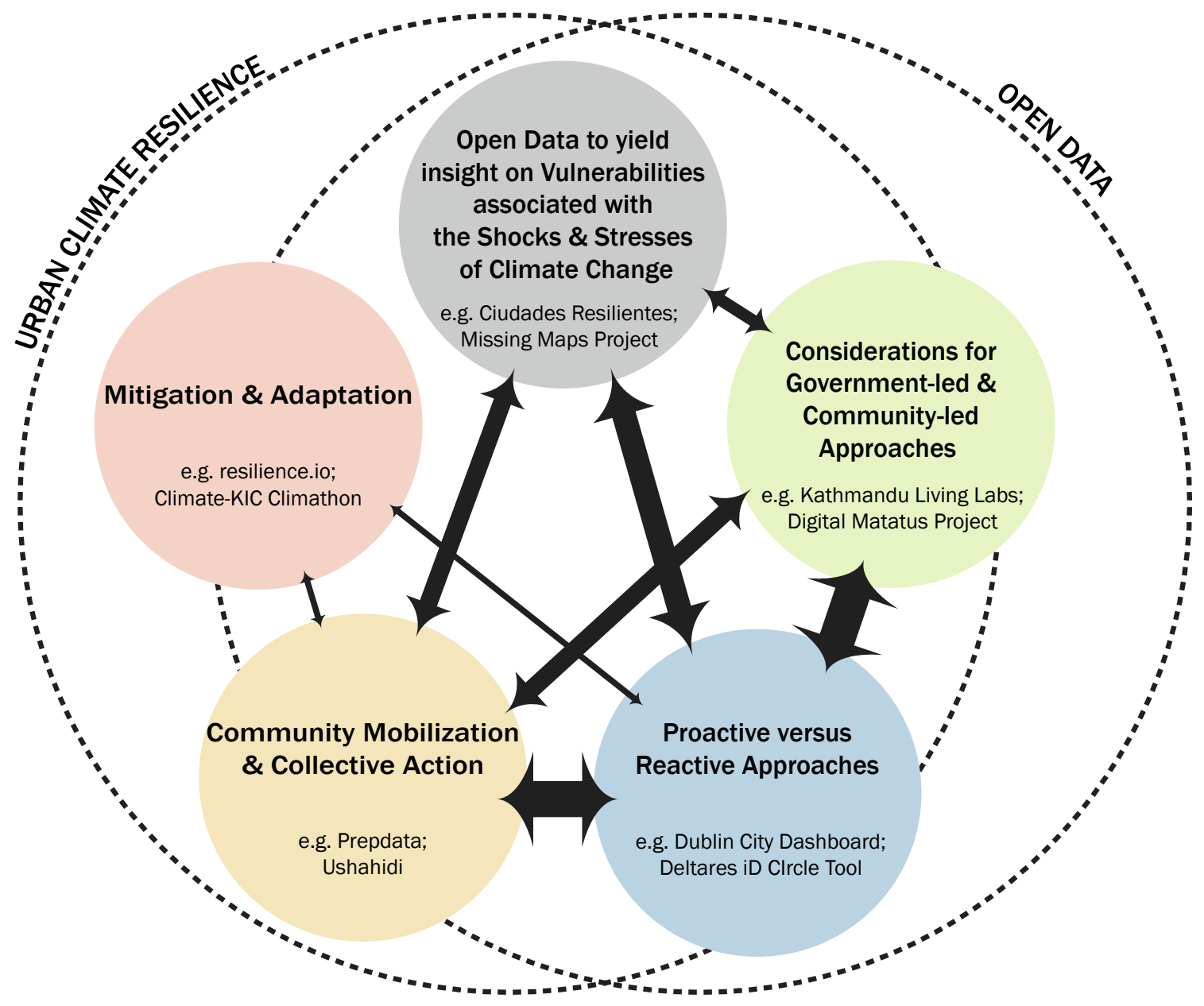

Figure 2: Interconnections between use cases and the five themes; the thickness of the arrow depicts the degree of use case overlap among various themes

\section{D.1 Open Data to help inform and act on Vulnerabilities associated with the Shocks and Stresses of Climate Resilience}

There are a number of different ways in which open data can help a city determine and act upon what makes their infrastructure and communities vulnerable. Under this theme, the Missing Maps Project and the Deltares iD CIrcle tool offer differing and distinct methods for uncovering vulnerability and managing risk using open data and mapping to improve urban resilience.

\section{D.1.1 Missing Maps Project}

The Missing Maps Project, is a collaborative project - between Médecin Sans Frontières, the American and British Red Cross, the Humanitarian OpenStreetMap Team, and others - that 
aims to create freely available, open digital maps for every human settlement in the world (Michael, 2014), with an initial goal to map 20 million inhabitants in vulnerable areas (Missing Maps, 2017). The project developed in response to a deficiency in accurate and informative maps for many cities in the Global South that house over a million people (Michael, 2014). Thus, the overarching objectives of the Missing Maps project are to: 1) create maps and develop spatial data for the "most vulnerable areas in the world" so that international and local organizations and other stakeholders are better equipped to respond to disasters or crises in those regions; and 2) contribute to the initiatives of OpenStreetMap, specifically the Humanitarian OpenStreetMap Team through the provision of technologies, frameworks, tools and techniques, and human capital (Missing Maps, 2017, para 1). The crowdsourcing methodology for the mapping of settlements lacking geographic data, developed by the Humanitarian OpenStreetMap Team, enables volunteers to participate from a distance (Michael, 2014). OpenStreetMap is a "volunteer-driven open data mapping platform" established through the not-for-profit OpenStreetMap Foundation (Missing Maps, 2017, para 12). Satellite imagery is made available through the OpenStreetMap software and volunteers around the world can log in and employ a point and click tool to delineate buildings, roads, green space, and water features. These maps are then given to volunteers on the ground who can add street and landmark names (Michael, 2014).

The idea of Missing Maps is to proactively map vulnerable areas prior to a disaster occurring (Missing Maps, 2017), thus this use case offers insight into Theme 3 as well, Proactive versus Reactive approaches. The Missing Maps Project in utilizing the OpenStreetMap software differs from proprietary measures such as Google Maps as it is open source. Thus, there is no cost associated with using Missing Maps - anyone, including local communities, can access, revise, and create through the project platform. The mapping of areas can yield insight for housing, waste strategies, transit planning, and economic development, while also pinpointing areas of risk or particular vulnerability (Michael, 2014). Missing Maps Project has been put into practice in places such as Rwanda, Zimbabwe, South Africa, and Bangladesh. The Project provides opportunities for local people to develop skills in using computers and other mapping and data tools, so that they 
can apply the maps to their planning and decision-making in the future (Missing Maps, 2017). The Missing Maps Project offers insight into the use of open data tools to uncover and map the most vulnerable places and inhabitants, striving to provide for a more comprehensive understanding of risk and threats in light of the impending effects of climate change.

\section{D.1.2 Deltares iD CIrcle Tool}

The Deltares iD CIrcle tool also uses mapping and open data to uncover vulnerability in a given place but in a much different manner than that of the Missing Maps Project. Deltares is an independent research institute in the Netherlands that specializes in exploring the sectors of water and subsurface (Deltares, n.d.a). Deltares has developed the CIrcle tool, standing for Critical Infrastructures: Relations and Consequences for Life and Environment, in their interactive data (iD) research laboratory. The CIrcle tool responds to the understanding that there is significant uncertainty surrounding the indirect impacts or "cascading effects" that result from an extreme weather event, in particular, flooding (Deltares, n.d.b, para 1). A pertinent challenge in understanding the cascading effects of a disaster or crisis is the lack of or difficulty in obtaining rigorous and effective data, most often as a result of privacy or confidentiality issues. Through two case studies in the Netherlands, Deltares demonstrates that cascading effects can be investigated and assessed using open data and expert information and perspectives (Deltares, n.d.b).

The CIrcle tool is employed through a touch table application platform that facilitates collaboration between stakeholders to explore cascading effects combining causal links identified by experts with flood models and open data. In using Open Earth Data, Deltares claims that open data accelerates the investigative process allowing for the exhibition of results rapidly that can then be evaluated by the stakeholders involved in the discussion. The CIrcle tool can be utilized for pre-emptive planning as well as disaster management and response while an emergency is occurring. The tool predominantly operates using qualitative data (Deltares, n.d.b). This supports Hunt and Watkiss' (2011) statement that investigations at the urban level are primarily based upon qualitative analyses. They go on to say that this will transform as governments and related stakeholders are expanding their 
responses from raising awareness to designing action-based responses (Hunt and Watkiss, 2011). Deltares found that the data on its own was not effective in determining and evaluating the effects of a given disaster. Rather, supporting interviews from key stakeholders are crucial to determining significant information and extracting relevance from the open data (Deltares, 2015).

The CIrcle tool is intended to be used in a workshop setting whereby experts and stakeholders can examine the results in real-time, providing pertinent information into the indirect impacts of extreme weather events and thus, contributing to climate change planning for resilient cities. While the CIrcle tool was initially intended for cascading effects analyses for flooding, it could be used for any natural disaster. Further, there are some indirect impacts that may apply ubiquitously and are thus useful to varying analyses (Deltares, 2015). For instance, the CIrcle tool was used in Cork, Ireland, identifying the vulnerable infrastructure or components using the interactive modelling platform to recognize and analyse the interconnectedness of infrastructure within the City. The CIrcle application allows for alterations to the data to determine the vulnerable areas or risks as well as experiment with safeguard solutions (Deltares, n.d.b). The interactive, immediate responses of the platform are useful in displaying the outcomes of protection measures for certain vulnerable objects.

There are a few challenges or considerations that arise from the use of open data, in the CIrcle tool, to determine the cascading effects that result from an extreme weather event. Deltares notes that having access to all the data is not necessary to develop an examination of the cascading effects. It would be interesting to further examine the effects of missing data that may result from concerns of privacy or confidentiality. Is there a lack of robustness that results? Is Deltares correct in claiming, "not all data is needed" (Deltares, 2015, p.2)? Another potential consideration concerns the stakeholders or experts involved in the cascading effects analysis and evaluation of the results from the CIrcle tool. It is important to consider who is at the table and whether there are key voices and perspectives missing from the conversation. Moreover, further research could explore the 
implications of adding more voices to the conversation and the processes employed to determine who should be involved in the dialogue.

\section{D.2 Considerations for Government-led and Community-led initiatives}

The theme, Considerations for government-led and community-led initiatives, explores the outset of an open data initiative for urban climate resilience. Under this theme, use cases were considered in terms of how they were established and supported, determining whether the initiative was established through bottom-up and outside government or topdown and inside government leadership or whether the initiative emerged out of a partnership or collaborative coordination between the two. This theme identifies use cases that fall under each of these three categories (i.e. bottom-up; top-down; and simultaneously bottom-up and top-down) yielding insight into how the use of open data tools for urban climate resilience emerges and expands and what motivates development.

\section{D.2.1 Ushahidi (Bottom-Up)}

Ushahidi is a crowd mapping organization that emerged in response to post-election violence in Kenya in 2007. Ushahidi, meaning witness or testimony in Swahili, serves as a prime example of a bottom-up, community or grassroots-led program as it was established by an impromptu collective of bloggers and technologists (Jeffery, 2011; Ushahidi, 2017a). The founders aimed to develop the crowd map initiative in an attempt to improve data collection and information sharing regarding the killings and violence occurring across Kenya post-election. Explored further in the context of theme 4, Ushahidi is open source whereby in its initial application, individuals could send in entries and reports regarding violence via mobile phones or email to provide a comprehensive outlook of the vicious action unfolding (Jeffery, 2011). Ushahidi had an impromptu, grassroots or community driven emergence that was in direct response to a shock. Since its emergence, applications of Ushahidi have evolved and expanded whereby the crowd mapping strategy has been utilized to map the impacts of the earthquake in Haiti in 2010, map the repercussions of the BP oil spill on surrounding communities, identify inconsistencies in the Nigerian election, and display the effects of the earthquake and tsunami in Japan. What started as a collective of technologists and bloggers combining forces in a time of duress has transformed into a 
US-registered, non-profit organization with more than 10 employees working in the United States and Africa (Jeffery, 2011). The Ushahidi platform is applicable to varying locations and issues allowing for expansion of scale and scope.

\section{D.2.2 Climate-KIC Climathon (Top-Down)}

Climate-KIC, Europe's principal public-private innovation partnership (Climate-KIC, n.d.c), has developed an annual hackathon, called a 'climathon', that aims to tackle a local climate change issue in a particular city (Climate-KIC, n.d.a). The Climate-KIC partnership involves academic institutions, the public sector, and businesses to explore innovative measures and strategies for climate change mitigation and adaptation (Climate-KIC, n.d.c). The Climathon, hosted by a city that has identified a context-specific issue, intends to target issues related to urban planning, city satellite data, infrastructure, and water usage. Participants are given 24 hours to develop their idea and then introduce it to a jury of local stakeholders (ClimateKIC, n.d.a).

In 2016, there were Climathons in 59 cities in 6 continents with over 1400 applications in topics such as air pollution, extreme weather, and smart city (Climate-KIC, n.d.b). For instance, Trondheim, Norway hosted a Climathon in January 2016, with the help of Climate-KIC and the Norwegian University of Science and Technology (NTNU). The hackathon or Climathon concentrated on the issue of carbon dioxide emissions caused by transport and more particularly, the difficulty in obtaining data relevant to achieving a $20 \%$ reduction in transport emissions. The Trondheim Climathon focused on three concerns pertaining to 1) hardware (e.g. need for affordable open source sensor systems); 2) software (e.g. utilizing open data in connection with official emissions reports); and 3) planning and policy (e.g. how can data collected from sensors be used in realizing change) (Climathon-KIC, 2016). The Trondheim Climathon serves as a specific example of the use or exploration of open data tools to build urban climate resilience, in this case related to transport emissions. For the purposes of this research, the Climathons are top-down or inside government as they are initiatives led by the government as part of a larger initiative developed under the umbrella of the European partnership, Climate-KIC. Some of the winning ideas from the 2016 Climathons, taking place in 59 cities, include using buses as 
filtration systems to combat air pollution and the creation of a series of green roofs that also collect data pertaining to the surrounding local area (Climate-KIC, n.d.b). In contrast to Ushahidi, Climate-KIC's Climathons are government-led strategies that consider the role of open data in tackling issues associated with urban resilience when confronted with a changing climate. While differing in origin, both initiatives have a common goal in striving to build resilient cities cognizant of the need for accessible and accountable data. Further research on the implications of the origins or catalysts for initiatives that are communityled or government-led could yield valuable insight into the motivations that drive change, conflicting or overlapping priorities, and whether the processes behind bottom-up and topdown strategies are significantly different and worthy of distinction.

\section{D.2.3 Kathmandu Living Labs (Joint Bottom-Up and Top-Down)}

Kathmandu Living Labs is a civic technology company that develops "digital infrastructure" for use by governments, companies, and non-profits to create tools for improved service provision for citizens (Kathmandu Living Labs, 2017b, para 2). The vision of Kathmandu Living Labs is to combine data, technology, and people to have a positive effect on day-today lives. The company aims to "put problems before solutions, people before technology, and data before opinions" (Kathmandu Living Labs, 2017a, para 2). Kathmandu Living Labs, paralleling the work of Ushahidi and the Missing Maps Project, demonstrates how cultivating "local data ecosystems" can enhance a city's capacity to act during and following a disaster (Roberts, 2015a, para 1). Kathmandu Living Labs serves as an example of an initiative that originated somewhere in between - merging top-down, government-led and bottom-up, community-led.

Kathmandu Living Labs officially emerged through the collaboration of Robert Soden and Nama Budhathoki. Inspired by the humanitarian digital infrastructure that contributed to emergency response after the earthquake in Haiti in 2010, Nama Budhathoki considered the vulnerabilities and challenges facing his home and thus created a citizen mapping initiative coordinating volunteers to map the Kathmandu Valley, pre-emptively, prior to a disaster (Wall, 2016). In the Fall of 2012, the World Bank's Global Facility for Disaster Reduction and Recovery was seeking to implement their Open Data for Resilience Initiative 
(OpenDRI) in several countries, including Nepal. Robert Soden, an employee of the World Bank, approached Nama, who was in the midst of championing an open mapping volunteer strategy in Nepal. OpenDRI was initiated in Nepal later that Fall and after its success, the Kathmandu Living Labs was created, as a non-for profit civic technology company in 2013, as a means of ensuring and furthering long-term connections and strategies for collaboration (Kathmandu Living Labs, 2017a). Thus, the company emerged from topdown and bottom-up leadership - building on a bottom-up, citizen mapping project and coordinating with the top-down, global GFDRR Open Data for Resilience Initiative.

In April 2015, Kathmandu Living Labs was challenged with applying their mapping tools when a 7.8 earthquake struck Kathmandu Valley killing 8000 people and uprooting 2 million (Roberts, 2015a). Kathmandu Living Labs was quick to act, establishing an outdoor office in a parking lot, due to aftershock, one day after the earthquake hit (Roberts, 2015a). Global volunteers revised the maps and datasets created in advance of the earthquake. These updated maps and corresponding data were then used by local organizations, the military in Nepal, MapAction, and the United Nations. Wall (2016), in an article in The Guardian, claims that this was the first emergency in which a local organization took a principal role to this degree. Kathmandu Living Labs and their volunteer-based citizen mapping allow for the consolidation of knowledge, highlighting the importance of the local context while fostering "collective intelligence" (Budhathoki via Wall, 2016, para 16). Wall (2016) goes on to state that Nama Budhathoki and MapAction concur that the "crowdsourcing phenomenon" is fundamentally changing disaster response" (para 15). Kathmandu Living Labs serves as an interesting example of a hybrid between communityled and government-led or top down initiatives. In this instance, Nama and his community of volunteers fulfills the community-led portion and the World Bank acts as the top-down actor. ${ }^{1}$ Yet, a prominent challenge for Kathmandu Living Labs is insufficient funds and a lack of financial support despite their supposed importance and substantial contributions to emergency response (Wall, 2016). There is a need for further and extensive

\footnotetext{
${ }^{1}$ For the purposes of this research, government agencies and international institutions such as the World Bank Group, United Nations, and Climate-KIC are considered top-down actors and fall within the category of government-led.
} 
conversations to take place among stakeholders in humanitarian agencies, large organizations, governments, and civic technology companies (Wall, 2016), to determine how communication and collaboration can be improved in the future.

The three use cases, Ushahidi, Climate-KIC, and Kathmandu Living Labs, act as snapshots of possible inceptions of the use of open data tools to build urban climate resilience. An initiative may arise from a bottom-up, community-led endeavour or a top-down, government-led undertaking. Further, as made evident through the Kathmandu Living Labs, initiatives that employ open data for urban climate resilience might have beginnings that are a hybrid between top-down and bottom-up, involving partnerships between international organizations, governments at various scales, and community organizations. Yet, despite an origin as community- or government-led or somewhere in between, initiatives may transform over time to involve more stakeholders - gaining different perspectives and growing in diverse directions. For instance, despite its impromptu, grassroots-based beginnings, Ushahidi is now employed by a wide variety of governmentled or high level international organizations such as the World Bank, the American Red Cross, the United Nations, and the United States of America (Ushahidi n.d.b). Moreover, the organization evolved through partnerships with companies and organizations such as Google, the Rockefeller Foundation, and the United States Agency for International Development (USAID) (Ushahidi, 2017a). Initiatives are transformative, emerging from a certain priority, incentive, or mobilization and evolving in response to incoming threats and available resources.

\section{D.3 Proactive versus Reactive approaches}

In exploring the use cases through the theme, Proactive versus reactive approaches, initiatives were examined based on whether they were pre-emptive or responsive. This research acknowledges that there are circumstances and impacts that are unforeseen or unexpected, and thus drive the need for issue-based action. Further, it is possible that a reactive response is needed although there has been an overall proactive approach. Yet, while reactive responses may transpire and might be necessary when faced with an unforeseen emergency or shock, urban resilience depends on proactive, systems-based 
planning and decision-making to ensure that cities are able to prepare for and endure change.

\section{D.3.1 Dublin City Dashboard}

As the concept of openness and transparency gains prevalence and data becomes increasingly accessible outside of governments, other stakeholders are using data to administer investigations, develop products and services, and build urban dashboards (Kitchin et al, 2016). The Dublin City Dashboard, established in 2014, is an example of a holistic strategy that utilizes open data to conceive a picture of the local city ecosystem (Kitchin et al, 2016; Maynooth University, n.d.a). The Dublin City Dashboard is comprised of detailed real-time and time series indicator data that are then portrayed in thousands of interactive maps and visualizations (Maynooth University, n.d.a). The Dashboard also allows for comparisons within the City of Dublin and among other cities, connects users with other city applications, and provides the opportunity for users to inform city officials of any issues (Kitchin et al, 2016). The Dashboard, created by The Programmable City project and the All Island Research Observatory at Maynooth University in partnership with Dublin City Council, has a target audience of companies, public sector practitioners, and citizens. The data, maps, and visualizations are to be used for evidence-based investigation, planning, and decision-making for Dublin City (Maynooth University, n.d.a).

Dublin City Dashboard employs open source tools where possible and is comprised of a series of indicator programs that aim to answer questions such as 1) "How well is Dublin performing?"; 2) “How does Dublin compare to other places?”; and 3) "What's happening in the city right now?" (Kitchin et al, 2016, p.95). The contents of the Dashboard are organized into a series of categories such as Dublin Reporting; Dublin RealTime; How's Dublin doing; and Dublin Apps (Maynooth University, n.d.b). Dashboards, as "translators and engines" as opposed to "mirrors", provide visual interpretations that users can access, coordinate, and work with through the digital framework (Kitchin et al, 2016, p.94). For instance, users can find specific data sets, extract data that they deem extraneous, collect information about the datasets, explore interactions among the data, and superimpose datasets to analyze potential connections (Kitchin et al, 2016). The Dublin City Dashboard is comprised of data 
and interactive visualizations related to population, economy, housing, crime, and environment (Maynooth University, n.d.a). Related to environment, there are real-time data visualizations pertaining to weather, water levels, air quality, and noise (Maynooth University, n.d.b). The data comes from a number of creators including the Dublin City Council, Central Statistics Office, and Dublinked (i.e. Dublin's Open Data catalogue) (Maynooth University, n.d.a; Kitchin et al, 2016). The Dublin City Dashboard is free for anyone to use and can be accessed online, with no need for the user to know mapping or graphic techniques (Maynooth University, n.d.a; Kitchin et al, 2016). Further, the corresponding data used to develop the applications, maps, and visualizations on the Dashboard are also free to use (Maynooth University, n.d.a), so that people are able to take the data and make products and services.

Urban dashboards can be useful to city practitioners in providing insight into cost-efficient service provision, to businesses in determining local demand and supply, and to citizens in yielding information about the current status of diverse factors within the City (Kitchin et al, 2016). Dashboards are, however, not entirely rational or comprehensive, but rather, inherently influenced by the perspectives of the creation team (Kitchin et al, 2016). In their paper, The praxis and politics of building urban dashboards, Kitchin et al (2016) argue that a "dashboard is a complex socio-technical assemblage of actors and actants that work materially and discursively within a set of social and economic constraints, existing technologies and systems, and power geometries to assemble, produce, and maintain the website" (p.96). In evaluating success, it is thus important to acknowledge that although urban dashboards strive to be extensive, they are inescapably limited, given constraints of access, for instance, or numerous possibilities for visualization, or as a result of the constantly changing and evolving city in which they are trying to represent. As a result, dashboards must be systems-based striving to anticipate alterations and transformations within the city, with the digital infrastructure growing "contextually, contingently, and relationally" alongside the changing urban system (Kitchin et al, 2016, p.100).

While heavily influenced by the broader institutional environment in which it was created, the Dublin City Dashboard also had circular impacts on the environment. Kitchin et al 
(2016) found that the Dashboard provided information on how the urban centre was organized and operating as well as the fragmentary components of the Dublin City Council governance framework. The Dashboard also resulted in additional datasets being made accessible and open (Kitchin et al, 2016). The critiques given by Kitchen et al describing dashboards as "reductive, atomizing complex, contingent relationships into relatively simple visualized measures" (Kitchin et al, 2016, p.95) begs the questions of how can dashboards be improved? Or how can we use dashboards for urban resilience strategies bearing in mind their limitations? And is it possible to have an initiative that accurately represents the state of a city from every angle and every perspective? While beyond the scope of this research paper, it is worthwhile to consider the challenges that urban dashboards encounter in their role as an open data tool for building urban resilience in a changing climate. Are the data visualizations and interactive maps used in the Dublin City Dashboard only skimming the surface in terms of the multifaceted aspects of urban areas and can this be overcome? Despite the need to identify, address, and possibly overcome the challenges associated with urban dashboards, initiatives such as the Dublin City Dashboard offer an interesting lens into a proactive measure for developing shared knowledge and understanding of an urban system.

\section{D.4 Community Mobilization and Collective Action}

Many of the use cases explored in this research strive to engage communities or a subset of stakeholders to work with open data and use it for improved resilience planning, decisionmaking, and overall well being. The analysis of this theme turns to Ushahidi, once again, as well as emergency response during an earthquake in Christchurch, New Zealand to highlight strategies for empowering community members, fostering inclusivity, and driving collective action in building and governing for climate resilience.

\section{D.4.1 Ushahidi}

As discussed in the analysis for the second theme, Considerations for government-led and community-led initiatives, Ushahidi is a crowdsourcing initiative headquartered in Nairobi and supported by a global team (Ushahidi, 2017a) that aims to foster a "local technology ecosystem" (Roberts, 2015b, para 1). As such, Ushahidi is rooted in the understanding that 
in order to effectively govern for resilience in cities, thorough and precise data is necessary for proactive disaster risk management and planning (Roberts, 2015b). Ushahidi focuses on several items including data acquisition (e.g. real-time), operations, visualizations, notifications regarding transformations or revisions, and "enterprise systems" (Ushahidi, 2017b, para 5). Through partnerships with organizations such as Making All Voices Count and Resilience Network Initiative, Ushahidi strives to improve information availability, "empower citizens, and protect marginalized communities" (Ushahidi, 2017a, para 3). In doing so, Ushahidi uses open data to enhance interactions between citizens and local governments, discovering resilience in unanticipated areas (Roberts, 2015b).

Ushahidi frequently partners with the Rockefeller Foundation's 100 Resilient Cities movement focusing on engaging people who aren't usually a part of or potentially excluded from the dialogue (Roberts, 2015b). Ushahidi has emerged as the "de facto source for citizen-generated reports in relation to relief efforts" (video via Roberts, 2015b). A prime example of Ushahidi's efforts to enhance community engagement, foster mobilization, and facilitate collective action occurred in Semarang, Indonesia in partnership with Kolektif Hysteria, a local organization. This work, funded by the Rockefeller Foundation, demonstrates Ushahidi's intent to collaborate with local communities to realize credible change using civic technology. Alongside Hysteria, Ushahidi developed a 2-phased mapping strategy that encouraged community and local government collaboration to work together to address the essentials for Semarang. The process, referred to as PekaKota (city map in Indonesian) offered a fresh opportunity to enhance the citizen-government relationship. Pekakota uses OpenStreetMap to map buildings, roads and other parts of the City deemed significant. Within the first 7 weeks of the initiative, Ushahidi and Hysteria had trained 13 community members in how to use OpenStreetMap. 49,301 buildings and 654 roads were mapped which led to the next step of the process. The second step of PekaKota involved the consolidation of reports developed by local residents, on the Ushahidi platform, regarding distinctions and considerations for certain areas, places, or infrastructure such as hazards, particularly vulnerable regions or areas needing maintenance or upgrades (Roberts, 2015b; Roberts, 2015a). Following this step, one could then consider how areas or infrastructure could be developed and improved. In partnering with Hysteria and 
developing Pekakota, Ushahidi seized an opportunity in the lack of data in Semarang to not only facilitate the creation of intricate and robust geospatial data that is useful for both local government and communities, but also mobilize a community to work towards building their resilience.

A major priority of Pekakota and Ushahidi's responsibilities - as part of 100 RC's undertakings in Semarang - was fostering civic engagement and co-creation of data (Roberts, 2015b), ensuring inclusivity especially for those stakeholders who were missing or left out of the "official decision-making processes" (Roberts, 2015a, para 4). The PekaKota process included a twitter feed depicting instances of resident engagement and excitement as well as communications with local officials (Roberts, 2015a). PekaKota promoted a "shared understanding" of the City and enabled future collaborative planning and decision-making to take place with ideally secure exchanges between citizens and city officials (Roberts, 2015b, para 6). The collaboration between the global organization, Ushahidi, and the local organization, Kolektif Hysteria, offers interesting insight into ensuring climate action meaningfully involves local residents and takes into account the contextual systems of the city.

\section{D.4.2 Earthquake emergency response in Christchurch, New Zealand} Ushahidi's work with Hysteria in Semarang, Indonesia, serves as an example of a proactive measure (i.e. refer to B.8.3 Proactive versus reactive approaches) to fostering community mobilization and collective action in building climate resilience. In contrast, the earthquake emergency response in Christchurch, New Zealand provides insight into an initiative reacting directly to a sudden catastrophe. An earthquake hit Christchurch in February 2011, killing 185 people and causing disorder and destruction to a vulnerable city having already recently incurred costs from another earthquake (McMurren et al, 2016). Volunteers and practitioners banded together in response and recovery organizations to use open data, crowdsourcing, open source tools, and secure data distribution to act on the challenges arising from the disaster (McMurren et al, n.d.). They also created a web app comprised of crowdsourced details pertaining to the emergency - that was accessed 70,000 times within the first 48 hours of creation. A website was also created using open property 
data that allowed for citizens to check their homes and properties. Other initiatives were developed using open data, open source tools, and crowdsourcing such as a construction intension viewer and a competition for students to develop new building footprints (McMurren et al, 2016).

Only hours after the earthquake occurred, volunteers from New Zealand and elsewhere combined forces and created Eq.org.nz - a crowdsourced disaster map - using the Ushahidi platform. The map included information on roads that were closed, areas that experienced destruction, access to pertinent resources and operations, and communication regarding those who could give or needed assistance. People could contribute via a website communication platform, email, SMS, or tweets. Two days following the earthquake, Eq.org.nz had received 779 reports, 781 geographic positions, and 70,000 different people accessing the site (McMurren et al, 2016). The disaster response to the earthquake in Christchurch was vast, responsive, and immediate benefitting from the collective action of worldwide volunteers to ensure the City had the resources needed to efficiently react to and absorb the disruptive change.

To effectively strengthen the adaptive and resilient capacity of cities, governments must address the role of urban residents - individually and as businesses, communities, or institutions - in implementing solutions (Dale et al, 2012). Apart from during a sudden shock, the impacts of climate change often appear distant and overly complicated to residents (Gruber et al, 2015; Sheppard et al, 2011). The challenge, then, is how to engage stakeholders to recognize climate change as a direct threat while also realizing that effective and enduring solutions are impossible without collective action. To address this challenge, initiatives such as Ushahidi and the disaster management in response to the earthquake in Christchurch use open data to not only raise awareness about climate change and the need for building resilience but also give organizations, communities, and individuals an opportunity to play a prominent role in the solution. 


\section{D.5 Mitigation and Adaptation}

Both mitigation and adaptation strategies are essential to the development of a city resilient to the diverse and unprecedented effects of climate change. This theme considers how open data can be employed to build resilience to climate change in undertaking and accounting for the overlapping priorities of mitigation and adaptation.

\section{D.5.1 Resilience.io}

The final theme is explored through the use case, resilience.io, an open-source platform developed by the Ecological Sequestration Trust, that focuses on using data visualizations, scenario-building, and a "collaboration laboratory" to develop long-term action for resilience rather than short-term, issue-based reactions to shocks or stresses (Ecological Sequestration Trust, n.d.a; Ecological Sequestration Trust, n.d.c, para 9; Passmore and Schmidt, 2015). Resilience.io offers an interesting perspective into the merging of mitigation and adaptation initiatives exploring needs for investment, collaborative strategies, and integrated planning (Ecological Sequestration Trust, n.d.c). Resilience.io is the "world's first open-source, integrated human-ecology-economics systems/modelling platform that enables resilient disaster risk sensitive planning, policy-making, investment, and procurement for city-regions globally" (Ecological Sequestration Trust, n.d.c, para 1). The Ecological Sequestration Trust developed resilience.io to address the lack of knowledge regarding the interconnectedness of human, ecological, and economic systems (Ecological Sequestration Trust, n.d.a). The digital platform develops an integrated systems-based interpretation of a given city region to be employed for planning, investment, and policy-making (Ecological Sequestration Trust, n.d.c; Passmore and Schmidt, 2015). The five components, comprising the platform, include: 1) "data brokerage"; 2) "integrated systems"; 3) "collaboration laboratory"; 4) "accessibility"; and 5) "urban investment fund" (Ecological Sequestration Trust, n.d.c, para 7-11). Thus, the resilience.io platform intends to serve as an expansive resource for users to better understand the city-region as well as gather evidence for various purposes.

Resilience.io is open-source and cloud-based allowing people to access and download it via the Internet (Ecological Sequestration Trust, 2014). The platform enables the consolidation 
of data from a diverse array of sources such as satellite imagery, local, regional, and national open government data, private sector data, sensor systems, and crowdsourced materials (Ecological Sequestration Trust, n.d.c; Passmore and Schmidt, 2015). The data available through the platform falls within four different categories: "space, entity, agent, and process" (Ecological Sequestration Trust, 2015a, p.1). The data collected through the resilience.io platform can then be used to satisfy four different principles including exploring interdependent systems that comprise a city region, creating indicators, including financing and resources for economic, social, and environmental priorities; developing a tool to be used to assess decision-making; embarking on systemic issues; and realizing urban objectives (Ecological Sequestration Trust, 2015b). The Ecological Sequestration Trust acknowledges climate change action as a fundamental component of planning and building resilience. The resilience.io platform aims to facilitate opportunities for durable and creative methods of finance and investment to advance climate change mitigation and adaptation strategies (Ecological Sequestration Trust, 2014).

In addition to demonstrating an open data tool that prioritizes climate change mitigation and adaptation strategies in an integrated approach, resilience.io also connects to themes three and four: Proactive versus reactive approaches and Community mobilization and collective action. Resilience.io relates to theme three and four in striving to act preemptively, acknowledging the importance of a systems perspective as well as fostering community mobilization through their collaborative intelligence prerogative. The Ecological Sequestration Trust claims there is a prominent role for an NGO that works to foster coordination among the public and private sectors and "champion new and effective means of involving communities" (Passmore and Schmidt, 2015, p.10). The Trust has coined the term "collaboratory" (i.e. collaboration laboratory) to describe the space in which collaborative intelligence is fostered - a process that drives shared understanding, symbiotic relationships, and capacity building to meet collective objectives that take into account varying perspectives and communities (Ecological Sequestration Trust, n.d.c, para 9). They assert that the "collaborative intelligence" established through the resilience.io platform will assist in addressing the challenges and risks resulting from shocks and stresses pertaining to climate change, resource deficiencies, environmental destruction, 
and extreme weather events (Ecological Sequestration Trust, n.d.a, p.1). When the first version of resilience.io is available for widespread download, further details on the collaboratory exploring what specific aspects it entails, who is involved, and how it is enacted in each city-region that employs resilience.io would help inform the effectiveness of the tool in fostering collective climate action.

Resilience.io is being created in a phased process whereby the Ecological Sequestration Trust places high value on prototypes and demonstrations to experiment with the modelling platform and interface. Moreover, the Trust aims for resilience.io to work alongside and integrate open data catalogues and frameworks as they materialize around the world, so that the platform is relevant and open to the city-region in which it is representing (Passmore and Schmidt, 2015). There are regional demonstrator projects occurring in the Greater Accra Metropolitan Area (GAMA), Accra; Ulaanbaatar, Mongolia; and Dorset, United Kingdom (Ecological Sequestration Trust, n.d.b). The timeline for the proliferation of resilience.io is from 2015-2019 incorporating time for development of the platform, repetitive experimentation, pilot projects in various locations, and then finally introduction of the first version of resilience.io. Once the first version is released, any cityregion can download resilience.io and work with local stakeholders to develop a contextspecific, tailored platform (Passmore and Schmidt, 2015). Resilience.io is a unique tool that is grounded in the need for an integrative and collaborative systems approach that prioritizes both climate change adaptation and mitigation. Further in prioritizing open access and the development of collaborative intelligence, the resilience.io tool has the potential to influence and reach diverse stakeholders and approaches. While still in the demonstrator phase of the project thus, yielding uncertainty surrounding the direct and indirect impacts of the software, resilience.io is a tool that could assist cities in collaborating among communities of practice and integrating the informal and formal strategies occurring within a city to build climate resilience and effectively act on adaptation and mitigation. 


\section{D.6 Lessons from Exploration of Use Cases}

These eight use cases are versatile, intricate initiatives ranging from hackathons that tackle a specific urban issue arising from climate change to a global digital platform that integrates human, ecological, and economic systems through evidence-based, visual techniques to grassroots mapping initiatives that uncover a city's vulnerable areas. While diverse in scope, nature, and origin, they depict a broad spectrum of possibility for the convergence of the open data and urban resilience communities of practice. They demonstrate how open data tools enhance urban resilience; to better confront, prepare for, and overcome the pressures and threats that stem from a changing climate. This analysis of use cases - explored through the five themes highlighting the avenues for the intersection of open data in urban climate resilience - does not suggest that a city striving to achieve climate resilience need only adopt or replicate one of these use cases to realize effective solutions. Rather these use cases, framed within the five themes, aim to instigate thinking and action that not only critically examines an urban planning approach rooted in resilience thinking but also understands that effective responses to climate change require evidence-based methods and robust, accountable, and transparent data. 


\section{E. NEXT STEPS}

In light of the rapidly increasing effects of climate change from sea level rise to droughts, governments at all levels are realizing the drastic and immediate need to adjust their practices (Field et al, 2014; Luka and Lister, 2000; Henson, 2006; Williams, 2009). To address climate change proactively and systemically, cities need to be cognizant of their contextual risks and govern for resilience in a manner that is evolutionary, evidence-based, and experimentative. Resilience - when confronted with the unprecedented and extensive impacts of climate change - requires innovative, collaborative solutions that hinge upon the openness and availability of current and contextual geospatial data (World Bank, 2017). As such, the purpose of this research is to explore the intersection of open data and urban climate resilience. Framed by the core question: how can open data tools and techniques be integrated within climate change planning to build urban resilience and instigate a sense of agency and collective action among stakeholders? this research seeks to shed light on the potential for open data tools to strengthen urban climate resilience. Five key themes formed the foundation for the analysis, illustrating the capacity of open data - bearing in mind its limitations - to directly support resilience priorities. The themes are as follows: 1) Open data to help inform and act on vulnerabilities associated with the shocks and stresses of climate resilience;

2) Considerations for government-led and community-led initiatives;

3) Proactive versus reactive approaches;

4) Community mobilization and collective action; and

5) Mitigation and adaptation.

The exploration of international use cases through the five themes highlight the potential for open data tools to merge with, complement, and advance urban climate resilience, while also indicating opportunities, challenges, and areas of considerations. This research intends to inform and inspire both the open data and resilience communities of practice, including government officials, civil society organizations, and urban planners, about the potential for collaborative strategies. These collaborative strategies as seen through the international use cases not only contribute to the building of a climate resilient city but also 
promote the need for accountable and transparent data frameworks for effective decisionmaking and planning.

This paper seeks to spark a dialogue, between two communities of practice that are continuing to gain prevalence as separate entities and also, more recently, as integrated endeavours. Moving forward, there is work to be done in both communities of practice recognizing a pertinent role for open data tools in urban resilience strategies that must be moulded, evaluated, and adapted based on a city's contextual needs, shocks, and stresses. The following recommendations pertain to the open data community of practice:

- While the use cases explored aim to build climate resilience to different degrees, there is a need to determine measures of success and evaluate the effectiveness of a given initiative in directly or indirectly impacting climate change planning. This research, which could be conducted by open data institutes, for instance, would help to strengthen awareness and promote the use of open data.

- Limitations such as comparability, access, and approachable interfaces must be overcome to effectively integrate open data tools in building urban climate resilience. The World Council on City Data, or a similar organization, could coordinate research and action towards addressing these limitations.

- In cities developing resilience strategies (i.e. 100 Resilient Cities), local open data communities (e.g. Civic Tech Toronto) can foster collaboration with the practitioners leading these initiatives, paying particular attention to developing open data initiatives that address context-specific shocks and stresses.

As the practice is embracing resilience thinking, urban planning offers a unique perspective into the opportunities for local governments and community members to confront vulnerabilities and risks to climate change using open data. Future action in governing and planning for resilience that explores a socio-ecological framework encompassing open data tools could prove effective in understanding and addressing the various interconnected dynamics at play. As a member of the urban resilience community of practice, the following recommendations concern urban planners: 
- In the suite of tools used in planning, urban planners should consider how strategies that incorporate open data could benefit long-term processes and research addressing climate change yielding evidence-based insight and transparent, accountable findings. For instance, there are numerous open data tools for mapping that are hugely applicable to planning processes addressing both the shocks and stresses associated with climate change. The use of open data in performance indicators, as encouraged by the World Council of City Data, also presents a significant opportunity for integrating useful open data tools in climate change planning.

- Urban planners need to critically examine the problem definitions framing resilience in their urban centres, questioning resilience of 'what to what', what does normal entail, and how open data-driven procedures can further their goals.

- Organizations such as the Rockefeller Foundation's 100 Resilient Cities movement and Bloomberg Philanthropies can act as intermediaries in connecting urban planners with the open data community, encouraging the use of open data tools and providing insight into their integration within traditional planning structures. Planning education also has a role to play in activating the deployment of open data tools for climate change planning and urban resilience, more broadly. In examining civic technology and exploring the uses of open data in planning curriculum, planners are aware of the potential opportunities and challenges of open data from the outset and can work to integrate these tools into their practice.

Ultimately, this research confronts Thomas Berry's assertion that human society has never, prior to climate change, tackled an issue demanding such abrupt and fundamental changes (Berry, 1999). As such, it is necessary, moving forward, as urban areas increasingly encounter the inevitable impacts of climate change, that we consider what a resilient city entails, what tools, like open data, are pivotal to advancing pre-emptive, evidence-based, and holistic planning, and what is needed to foster 'a time is now' mentality. 


\section{APPENDIX: Use Cases}

1. Earthquake emergency response in Christchurch, New Zealand:

http://odimpact.org/case-new-zealands-christchurch-earthquake-clusters.html

2. Digital Globes:

http://www.unis.unvienna.org/unis/en/pressrels/2016/unisos465.html

3. Ushahidi https://www.ushahidi.com/

4. Uganda Bureau of Statistics National Statistical MetaData Dictionary:

http://www.education.go.ug/files/downloads/Printed\%20Second\%20Edition $\% 20$

of $\% 20$ the $\% 20$ National $\% 20$ Statistical\%20Metadata\%20Dictionary-

\%20April\%202016.pdf

5. Project Noah http://noah.dost.gov.ph/\#/

6. Mapping Forgotten Places (University of Miami): http://climate.miami.edu/builtenvironment/mapping-forgotten-places/

7. Missing Maps Project http://www.missingmaps.org/about/

8. Digital Matatus project: http://www.digitalmatatus.com/about.html

9. Global Facility for Disaster Risk and Reduction Open Cities Mapping Project:

http://www.worldbank.org/en/region/sar/publication/planning-open-citiesmapping-project

10. Deltares iD Lab's CIrcle Tool: https://www.deltares.nl/en/software/circle-criticalinfrastructures-relations-and-consequences-for-life-and-environment-2/

11. Prepdata: http://www.prepdata.org/about

12. Ciudades Resilientes: http://ciudades-resilientes.org/

13. Kathmandu Living Labs: http://www.kathmandulivinglabs.org/

14. Climate-KIC Climathon: https://climathon.climate-kic.org/

15. Dublin City Dashboard: http://www.dublindashboard.ie/pages/index

16. World Air Quality Index Project: https://waqi.info/

17. resilience.io: http://resilience.io/ 


\section{REFERENCE LIST}

Allman, L., Fleming, P., Wallace, A. (2004). The progress of English and Welsh local authorities in addressing climate change, Local Environment: The International Journal of Justice and Sustainability, 9, 271-283.

Bai, X. (2007). Integrating global environmental concerns into urban management: the scale and readiness arguments, Journal of Industrial Ecology, 11, 15-29.

Beilin, R. and Wilkinson, C (2015). Introduction: Governing for urban resilience, Urban Studies, 52(7), 1205-1217.

Belanger, F. and Carter, L. (2009). The Impact of the Digital Divide on E-Government Use, Communications of the ACM, 52(4), 132-135.

Berkowitz, M. (2015). Climate Change Is Not Enough. Retrieved from 100 RC website: http://www.100resilientcities.org/blog/entry/climate-change-is-not-enough\#/-_/

Berry, T. (1999). The Great Work, New York, Three Rivers Press, 1999.

Bertot, J.C., Gorham, U., Jaeger, P.T., Sarin, L.C., Choi, H. (2014). Big data, open government and egovernment: Issues, policies and recommendations, Information Polity, 19, 5-16.

Betsill, M., Bulkeley, H. (2007). Looking back and thinking ahead: a decade of cities and climate change research, Local Environment: The International Journal of Justice and Sustainability, 12, 447456.

Bloomberg Philanthropies. (2017a). About What Works Cities. Retrieved from What Works Cities Bloomberg Philanthropies website: https://whatworkscities.bloomberg.org/about/

Bloomberg Philanthropies. (2017b). Sustainable Cities. Retrieved from Bloomberg Philanthropies website: https://www.bloomberg.org/program/environment/sustainable-cities/\#overview

Broto, V.C., Bulkeley, H. (2013). A survey of urban climate change experiment in 100 cities, Global Environmental Change, 23, 92-102.

Bulkeley, H. (2010). Cities and the governing of climate change, Annual Review of Environment and Resources, 35, 229-253.

Canadian Institute of Planners. (n.d.). Statement of Values. Retrieved from Canadian Institute of Planners website: http://www.cip-icu.ca/Files/Exam-reading-list/Statement-of-Values-and-Codeof-Professional-Pract 
Caputo, S., Caserio, M., Coles, R., Jankovic, L., Gaterell, M. (2015). Urban resilience: two diverging interpretations, Journal of Urbanism, 8(3), 222-240.

Carpenter, S., Walker, B., Anderies, J.M., and Abel, N. (2001). From Metaphor to Measurement: Resilience of What to What? Ecosystems, 4, 765-781.

City of Vancouver. (2012). Greenest City 2020 Action Plan. Retrieved from City of Vancouver website: http://vancouver.ca/files/cov/Greenest-city-action-plan.pdf

Climate-KIC. (2016). Trondheim Climathon: Climate Smart through the Use of Data. Retrieved from Climate-KIC website: http://www.climate-kic.org/events/trondheim-climathon-climate-smart-usedata/

Climate-KIC. (n.d.a). Climathon. Retrieved from Climathon website: https://climathon.climatekic.org/

Climate-KIC. (n.d.b). Climathon 2016 Highlights. Retrieved from Climathon website: https://climathon.climate-kic.org/climathon-highlights/climathon-2016-highlights

Climate-KIC. (n.d.c). What is Climate-KIC? Retrieved from Climate-KIC website: http://www.climate-kic.org/about/

Collins, C. and Ison, R. (2009). Jumping off Arnstein's Ladder: Social Learning as a New Policy Paradigm for Climate Change Adaptation, Environmental Policy and Governance, 19, 358-373.

Dale, A., Dushenko, W.T., and Robinson, P. (2012). Urban Sustainability: Reconnecting Space and Place, United States, University of Toronto Press, 2012.

Davoudi, S. (2009) Introduction to Part 1. Chapter 2 in Davoudi, S., Crawford, J., Mehmood, A., eds. Planning for Climate Change: Strategies for Mitigation and Adaptation for Spatial Planners, London, Earth Scan.

Davoudi, S., Shaw, K., Haider, L.J., Quinlan, A.E., Peterson, G.D., Wilkinson, C., Fünfgeld, H., McEvoy, D., Porter, L., and Davoudi, S. (2012). Resilience: A Bridging Concept or a Dead End? "Reframing" Resilience: Challenges for Planning Theory and Practice Interacting Traps: Resilience Assessment of a Pasture Management System in Northern Afghanistan Urban Resilience: What Does it Mean in Planning Practice? Resilience as a Useful Concept for Climate Change Adaptation? The Politics of Resilience for Planning: A Cautionary Note, Planning Theory \& Practice, (13)2, 299-333, DOI: 10.1080/14649357.2012.677124

Davoudi, S., Bohland, J., Knox, P., and Lawrence, J. (2017). The Resilience Machine. Retrieved from Urban Resilience Research Net website: http://www.urbanresilienceresearch.net/2017/02/09/the-resilience-machine/ 
Dawes, S.S. (2010). Stewardship and usefulness: Policy principles for information-based transparency, Government Information Quarterly, 27, 377-383.

Deltares. (2015). CIrcle: Critical Infrastructures: Relations and Consequences for Life and Environment. Retrieved from Deltares website:

https://www.deltares.nl/app/uploads/2015/04/Productblad-CIrcle.pdf

Deltares. (n.d.a). About Us. Retrieved from Deltares website: https://www.deltares.nl/en/aboutus/

Deltares. (n.d.b). CIrcle - Critical Infrastructures: Relations and Consequences for Life and Environment. Retrieved from Deltares website: https://www.deltares.nl/en/software/circlecritical-infrastructures-relations-and-consequences-for-life-and-environment-2/

Domingo, Al., Bellalta, B., Palacin, M., Oliver, M., Almirall, E. (2013). Public Open Sensor Data: Revolutionizing Smart Cities, IEEE Technology and Society Magazine, Winter 2013, 50-56 10.1109/MTS.2013.2286421

Ecological Sequestration Trust. (2015a). Data Specification (abbreviated). Retrieved from Ecological Sequestration Trust website: http://ecosequestrust.org/wpcontent/uploads/2015/11/resilienceIO-data-specification-abbreviated.pdf

Ecological Sequestration Trust. (2015b). Functional Specification (abbreviated). Retrieved from Ecological Sequestration Trust website: http://ecosequestrust.org/wpcontent/uploads/2015/11/resilienceIO-functional-specification-abbreviated-.pdf

Ecological Sequestration Trust. (2014). The resilience.io Platform. Retrieved from Ecological Sequestration Trust website: http://ecosequestrust.org/wpcontent/uploads/2014/05/resilienceI0-1-page-glossy.pdf

Ecological Sequestration Trust. (n.d.a). Concept. Retrieved from resilience.io website: http://resilience.io/resilienceio/resilience-io-specification-documents/

Ecological Sequestration Trust. (n.d.b). Regional demonstrator projects. Retrieved from resilience.io website: http://resilience.io/regional-demonstrator-projects/

Ecological Sequestration Trust. (n.d.c). What is resilience.io? Retrieved from resilience.io website: http://resilience.io/resilience-io-supported-by-the-ecological-sequestration-trust/

Evans, J.P. (2011). Resilience, ecology and adaptation in the experimental city, Transactions of the Institute of British Geographers, 36, 223-237. 
Few, R., Brown, K., and Tompkins, E.L. (2007). Public participation and climate change adaptation: avoiding the illusion of inclusion, Climate Policy, 7, 46-59.

Field, C.B., V.R. Barros, D.J. Dokken, K.J. Mach, M.D. Mastrandrea, T.E. Bilir, M. Chatterjee, K.L. Ebi, Y.O. Estrada, R.C. Genova, B. Girma, E.S. Kissel, A.N. Levy, S. MacCracken, P.R. Mastrandrea, and L.L.White (eds.). (2014). Summary for policymakers. In: Climate Change 2014: Impacts, Adaptation, and Vulnerability. Part A: Global and Sectoral Aspects. Contribution of Working Group II to the Fifth Assessment Report of the Intergovernmental Panel on Climate Change Cambridge University Press, Cambridge, United Kingdom and New York, NY, USA, pp. 1-32.

Flyvbjerg, B. (2002). Bring Power to Planning Research: One Researcher's Praxis Story, Journal of Planning Education and Research, 21:4, 353-366.

Flyvbjerg, B. (1998). Rationality and power: democracy in practice. Chicago, University of Chicago Press.

Fox, M.S., and Pettit, C.J. (2015). On the Completeness of Open City Data for Measuring City Indicators, Proceedings of the IEEE Conference on Smart Cities, Guadalajara Mexico.

GFDRR. (2014). Open Data for Resilience Initiative Field Guide, Global Facility for Disaster Recovery and Reduction (GFDRR), International Bank for Reconstruction and Development, The World Bank. Retrieved from GFDRR website: https://www.gfdrr.org/sites/gfdrr/files/publication/opendri_fg_web_20140629b_0.pdf

Goldsmith, S. (2016). Predictive Analytics: Driving Improvements Using Data. Retrieved from Data Smart City Solutions website: http://datasmart.ash.harvard.edu/news/article/predictive-analyticsdriving-improvements-using-data-932

Gruber, J.S., Rhoades, J.L., Simpson, M., Stack, L., Yetka, L., Wood, R. (2015). Enhancing climate change adaptation: strategies for community engagement and university-community partnerships, Journal of Environmental Studies and Sciences.

Han, J., Pei, J., and Kamber, M. (2011). Data Mining: Concepts and Techniques, Waltham, MA, Morgan Kaufmann, 2012.

http://site.ebrary.com.ezproxy.lib.ryerson.ca/lib/oculryerson/reader.action?docID=10483440

Hanger, S., Pfenninger, S., Dreyfus, M., Patt, A. (2013). Knowledge and information needs of adaptation policy-makers: a European study, Regional Environmental Change, 13, 91-101

Headd, M. (2014). Real-Time Open Data. Government Technology. Retrieved from Gov Tech website: http://www.govtech.com/opinion/Real-Time-Open-Data.html

Henson, R. (2006). The Rough Guide to Climate Change, London, Rough Guides. 
Howard, J. (2009) Climate Change Mitigation and Adaptation in Developed Regions: A Critical Perspective on the Adaptation Turn in Urban Climate Planning. Chapter 2 in Davoudi, S., Crawford, J., Mehmood, A., eds. Planning for Climate Change: Strategies for Mitigation and Adaptation for Spatial Planners, London, Earth Scan.

Hunt, A. and Watkiss, P. (2011). Climate change impacts and adaptation in cities: a review of the literature, Climatic Change, 103, 13-49.

Innes, J.E. (1995). Planning Theory's Emerging Paradigm: Communicative Action and Interactive Practice, Journal of Planning Education and Research, 14, 183-189.

IPCC. (2014). Annex II: Glossary [Mach, K.J., S. Planton and C. von Stechow (eds.)]. In: Climate Change 2014: Synthesis Report. Contribution of Working Groups I, II and III to the Fifth Assessment Report of the Intergovernmental Panel on Climate Change [Core Writing Team, R.K. Pachauri and L.A. Meyer (eds.)]. IPCC, Geneva, Switzerland, pp. 117-130. Retrieved from IPCC website: https://www.ipcc.ch/pdf/assessment-report/ar5/syr/AR5_SYR_FINAL_Glossary.pdf

ISO/TC 268 Sustainable cities and communities, (2016). ISO 37101:2016: Sustainable development in communities -- Management system for sustainable development -- Requirements with guidance for use. Retrieved from ISO website:

http://www.iso.org/iso/home/store/catalogue_tc/catalogue_detail.htm?csnumber=61885

ISO. (n.d.). ISO 37120 briefing note: the first International Standard on city indicators. Retrieved from ISO website: https://www.iso.org/files/live/sites/isoorg/files/archive/pdf/en/37120_briefing_note.pdf

Janssen, M., Charalabidis, Y., Zuiderwijk, A. (2012). Benefits, Adoption Barriers and Myths of Open Data and Open Government, Information Systems Management, 29, 258-268.

Jeffery, S. (2011). Ushahidi: crowdmapping collective that exposed Kenyan election killings. Retrieved from the Guardian website: https://www.theguardian.com/news/blog/2011/apr/07/ushahidi-crowdmap-kenya-violencehague

Johnson, P. and Robinson, P. (2014). Civic Hackathons: Innovation, Procurement, or Civic Engagement?, Review of Policy Research, 31(4), 349-357.

Kathmandu Living Labs. (2017a). About. Retrieved from Kathmandu Living Labs website: http://www.kathmandulivinglabs.org/about

Kathmandu Living Labs. (2017b). Welcome. Retrieved from Kathmandu Living Labs website: http://www.kathmandulivinglabs.org/ 
Kirilenko, A.P. and Stepchenkova, S.O. (2014). Public microblogging on climate change: One year of Twitter worldwide, Global Environmental Change, 26, 171-182.

Kitchin, R., Maalsen, S., and McArdle, G. (2016). The praxis and politics of building urban dashboards, Geoforum, 77, 93-101.

Landry, J., Webster, K., Wylie, B., and Robinson, P. (2016). How can we improve urban resilience with open data? Retrieved from Open Data Institute website: https://drive.google.com/file/d/0B356JqI1-OL6RUtKOUloZWpZcmM/view

Lausch, A., Schmidt, A., and Tischendorf, L. (2015). Data mining and linked open data - New perspectives for data analysis in environmental research, Ecological Modelling, 295, p. 5-17.

Ligeti, E., Penney, J., Wieditz, I. (2007) Cities preparing for climate change: a study of six urban regions, Clean Air Partnerships, Toronto, 1-65.

Lister, N.M. (2015). Resilience: Designing the New Sustainability, The International Review of Landscape Architecture and Urban Design, 90, 14-21. Retrieved from Ecological Design Lab website: http://ecologicaldesignlab.ca/wpcontent/uploads/2016/08/Resilience_Designing_the_New_Sustainabil.pdf

Longo, J. (2011). \#OpenData: Digital-Era Governance Thoroughbred or New Public Management Trojan Horse, Public Policy \& Governance Review, 2(2), 38-51.

Lu, X., Wrathall, D.J., Sundsøy, P.R, Nadiruzzaman, Md., Wetter, E., Iqbal, A., Qureshi, T., Tatem, A., Canright, G., Engø-Monsen, K., and Bengtsson, L. (2016). Unveiling hidden migration and mobility patterns in climate stressed regions: A longitudinal study of six million anonymous mobile phone users in Bangladesh, Global Environmental Change, 38, p. 1-7.

Luka, N. and Lister, N.M. (2000). Our Place: Community ecodesign for the Great White North means re-integrating local culture and nature, Alternatives Journal, 26:3.

Manzo, L.C. and Perkins, D.D. (2006). Finding Common Ground: The Importance of Place Attachment to Community Participation and Planning, Journal of Planning Literature, 20:4, 335-350.

Maynooth University. (n.d.a). About Dublin Dashboard. Retrieved from Dublin Dashboard website: http://www.dublindashboard.ie/pages/ContactUs

Maynooth University. (n.d.b). Dublin Dashboard. Retrieved from Dublin Dashboard website: http://www.dublindashboard.ie/pages/index 
McMurren, J., Verhulst, S., Young, A. (2016). Open Data's Use after Christchurch Earthquakes. Open Data Impact, GovLab, Omidyar Network. Retrieved from ODI Impact's website:

http://odimpact.org/static/files/case-studies-new-zealand.pdf

McMurren, J., Verhulst, S., Young, A. (n.d.). New Zealand's Christchurch Earthquake Clusters.

Retrieved from Gov Lab website: http://odimpact.org/case-new-zealands-christchurchearthquake-clusters.html

Meerow, S., Newell, J.P., Stults, M. (2016). Defining urban resilience: A review, Landscape and Urban Planning, 147, 38-49.

Mehmood, A. (2016). Of resilient places: planning for urban resilience, European Planning Studies, 24(2), 407-419.

Michael, C. (2014). Missing Maps: nothing less than a human genome project for cities. Retrieved from The Guardian website: https://www.theguardian.com/cities/2014/oct/06/missing-mapshuman-genome-project-unmap

Miller, G. (2008). Getting to K(no)w Annual Report 2007-2008, Environmental Commissioner of Ontario, 1-224.

Missing Maps. (2017). About. Retrieved from Missing Maps website:

http://www.missingmaps.org/about/

Mitchum, R. (2016). Chicago Becomes First City to Launch Array of Things. Retrieved from Computation Institute website: https://ci.uchicago.edu/press-releases/chicago-becomes-first-citylaunch-array-things

Nam, T. (2012). Suggesting frameworks of citizen-sourcing via Government 2.0, Government Information Quarterly, 29, 12-20.

Newman, L. and Dale, A. (2005). The role of agency in sustainable local community development, Local Environment, 10:5, 477-486.

Open Knowledge International. (n.d.). Open Data Handbook. Support from: Shuttleworth Foundation, The World Bank, Open Data for Development Network. Retrieved from Open Data Handbook website: http://opendatahandbook.org/guide/en/introduction/

Passmore, S. and Schmidt, A. (2015). resilience.io A revolution in planning. For The Department for International Development (DfiD) and Cities Alliance by The Ecological Sequestration Trust. Retrieved from Ecological Sequestration Trust website: http://ecosequestrust.org/wpcontent/uploads/2015/02/resilience.io-platform-report.pdf 
Roberts, S. (2015a). Kathmandu \& Semarang: Community Mapping and Open Data in Two Cities. Retrieved from 100 Resilient Cities website:

http://www.100resilientcities.org/blog/entry/kathmandu-semarang-citizen-engagement-andopen-data-mapping-in-two-cities\#/-_Yz5jJmg\%2FMSd1PWI\%3D/

Roberts, S. (2015b). Mapping Community Resilience in Indonesia \{Video\}. Retrieved from Ushahidi website: https://www.ushahidi.com/blog/2015/08/10/mapping-community-resilience/

Robinson, P and Gore. C. (2015). "The Spaces In Between: A comparative analysis of municipal climate governance and action". Environment and Planning C: Government and Policy, 47: 1-18.

Robinson, P.J and Johnson, P.A. (2016). Civic Hackathons: New Terrain for Local GovernmentCitizen Interaction?, Urban Planning, 1(2), 65-74.

Robinson, D.G, Yu, H., Felten, E.W. (2010). Enabling Innovation for Civic Engagement, in Lathrop, D. and Ruma, L., eds., Open Government: Collaboration, Transparency, and Participation in Practice. O’Reilly: Sebastopol, CA, 83-90.

Rockefeller Foundation. (2017). 100 Resilient Cities. Retrieved from 100 Resilient Cities website: http://www.100resilientcities.org/\#/-_Yz5jJmg\%2FMSd1PWI\%3D/

Rodin, J. (2017). What is the next frontier for climate change resilience? Retrieved from the Rockefeller Foundation website: https://www.rockefellerfoundation.org/insights/insightsdetail/\#what-is-the-next-frontier-for-climate-change-resilience

Roy, J. (2014). Open Data and Open Governance in Canada: A Critical Examination of New Opportunities and Old Tensions, Future Internet, 6(3), 414-432.

Sager, T. (2002). Power Concentration or Manipulation in the Planning Process, in T. Sager, Democratic Planning and Social Choice Dilemmas, Hampshire UK, Ashgate Publications, 2002, pp.181-203.

Sheppard, S.R.J., Shaw, A., Flanders, D., Burch, s., Wiek, A., Carmichael, J., Cohen, S. (2011). Future visioning of local climate change: A framework for community engagement and planning with scenarios and visualisation, Futures, 43 (4), 400-412.

Shueh, J. (2015). How to Successfully Harvest Value from Open Data. Government Technology. Retrieved from Gov Tech website: http://www.govtech.com/data/How-to-Successfully-HarvestValue-From-Open-Data.html

Sieber, R.E. and Johnson, P.A. (2015). Civic open data at a crossroads: Dominant models and current challenges, Government Information Quarterly, 32, 308-315. 
Sinclair, A.J. and Diduck, A. (2005). Public Participation in Canadian Environmental Assessment: Enduring Challenges and Future Directions, in K.S. Hanna, ed. Environmental Impact Assessment: practice and participation, Ontario, Oxford University Press, 2005, pp.53-74.

Speer, P.W. and Hughey, J. (1995). Community Organizing: An Ecological Route to Empowerment and

Power, American Journal of Community Psychology, 23:5, 729-748.

Stebbins, R.A. (2001). Qualitative Research Methods: Exploratory Research in the Social Sciences. SAGE Publications Ltd. DOI: 10.4135/9781412984249

Tippett, J., Handley, J.F., and Ravetz, J. (2007). Meeting the challenges of sustainable development A

conceptual appraisal of a new methodology for participatory ecological planning, Progress in Planning, 67, 9-98.

UNDP. (2007). Adaptation to climate change: Doing development differently, United Nations, 1-4.

UNFCCC. (2016). Conference of the Parties: Report of the Conference of the Parties on its twentyfirst session, held in Paris from 30 November to 15 December, 2015, United Nations Framework Convention on Climate Change, 1-36.

Ushahidi. (2017a). About Ushahidi. Retrieved from Ushahidi website:

https://www.ushahidi.com/about

Ushahidi. (2017b). Powerful Features. Retrieved from Ushahidi website:

https://www.ushahidi.com/features

Ushahidi (2017c). Ushahidi. Retrieved from Ushahidi website:

https://www.ushahidi.com/

Wagenaar, H. and Wilkinson, C. (2015). Enacting Resilience: A Performative Account of Governing for Urban Resilience, Urban Studies, 52(7), 1265-1284.

Wall, I. (2016). Could mapping tech revolutionise disaster response? Retrieved from The Guardian website: https://www.theguardian.com/global-development-professionals-

network/2016/apr/25/could-mapping-tech-revolutionise-disaster-response?CMP=share_btn_tw

Williams, T. (2009). Climate Change: Adaptation, Library of Parliament: Industry, Infrastructure and Resources Division, 1-10.

Wilson, E. (2006). Adapting to Climate Change at the Local Level: The Spatial Planning Response, Local Environment: The International Journal of Justice and Sustainability, 11(6), 609-625. 
Wolf, J. and Moser, S.C. (2011). Individual understandings, perceptions, and engagement with climate change: insights from in-depth studies across the world, Wiley Interdisciplinary Reviews: Climate Change, 2(4), 547-569. DOI: 10.1002/wcc.120

The World Bank. (2017). Planning an Open Cities Mapping Project. Retrieved from the World Bank website: http://www.worldbank.org/en/region/sar/publication/planning-open-cities-mappingproject.

World Council on City Data (WCCD). (n.d.). Created by Cities, For Cities. Retrieved from Data for Cities website: http://www.dataforcities.org/wccd/

Zuiderwijk, A. and Janssen, M. (2014). Open data policies, their implementation and impact: A framework for comparison, Government Information Quarterly, 31, 17-29. 


\section{GLOSSARY}

Open Data: "data that can be freely used, reused and redistributed by anyone - subject only, at most, to the requirement to attribute and sharealike" (Open Knowledge International, n.d., p.3).

Climate change: "Climate change refers to a change in the state of the climate that can be identified (e.g., by using statistical tests) by changes in the mean and/or the variability of its properties and that persists for an extended period, typically decades or longer. Climate change may be due to natural internal processes or external forcings such as modulations of the solar cycles, volcanic eruptions and persistent anthropogenic changes in the composition of the atmosphere or in land use. Note that the Framework Convention on Climate Change (UNFCCC), in its Article 1, defines climate change as: 'a change of climate which is attributed directly or indirectly to human activity that alters the composition of the global atmosphere and which is in addition to natural climate variability observed over comparable time periods'. The UNFCCC thus makes a distinction between climate change attributable to human activities altering the atmospheric composition and climate variability attributable to natural causes" (Working Groups 1, 2 \& 3; IPCC, 2014, p.120).

Mitigation: "A human intervention to reduce the sources or enhance the sinks of greenhouse gases (GHGs)" (Working Groups 1, 2 \& 3; IPCC, 2014, p.125).

Adaptation: "The process of adjustment to actual or expected climate and its effects. In human systems, adaptation seeks to moderate or avoid harm or exploit beneficial opportunities. In some natural systems, human intervention may facilitate adjustment to expected climate and its effects" (Working Groups 2 \& 3; IPCC, 2014, p.118).

Metadata: "Information about a dataset such as its title and description, method of collection, author or publisher, area and time period covered, licence, date and frequency of release, etc." (Open Knowledge Foundation, n.d., p.8). 